NBER WORKING PAPER SERIES

\title{
CAN EMPLOYMENT REDUCE LAWLESSNESS AND REBELLION? A FIELD EXPERIMENT WITH HIGH-RISK MEN IN A FRAGILE STATE
}

\author{
Christopher Blattman \\ Jeannie Annan \\ Working Paper 21289 \\ http://www.nber.org/papers/w21289 \\ NATIONAL BUREAU OF ECONOMIC RESEARCH \\ 1050 Massachusetts Avenue \\ Cambridge, MA 02138 \\ June 2015
}

The intervention was designed and implemented by Action On Armed Violence in cooperation with Robert Deere, David Elliot, Melissa Fuerth, Christine Lang and Sebastian Taylor. For comments we thank Steve Archibald, Eli Berman, Erwin Bulte, Amanda Clayton, Alexandra Hartman, Macartan Humphreys, Larry Katz, Supreet Kaur, Stathis Kalyvas, Mattias Lundberg, Mike McGovern, Mushfiq Mobarak, Eric Mvukiyehe, Suresh Naidu, Rohini Pande, Celia Paris, Paul Richards, Cyrus Samii, Raul Sanchez de la Sierra, Jacob Shapiro, Chris Udry, Steven Wilkinson, the anonymous referees, and seminar participants at Columbia, Cornell, Princeton, Stanford, Yale, IFPRI, the World Bank, and University of Washington. Abhit Bhandari, Philip Blue, Natalie Carlson, Camelia Dureng, Mathilde Emeriau, Tricia Gonwa, Rebecca Littman, Richard Peck, Gwendolyn Taylor, Xing Xia, and John Zayzay provided research assistance through Innovations for Poverty Action (IPA). Data collection was supported by the UN Peacebuilding Fund (via UNDP) and the World Bank's SIEF and CHYAO trust funds. The views expressed herein are those of the authors and do not necessarily reflect the views of the National Bureau of Economic Research.

NBER working papers are circulated for discussion and comment purposes. They have not been peerreviewed or been subject to the review by the NBER Board of Directors that accompanies official NBER publications.

(C) 2015 by Christopher Blattman and Jeannie Annan. All rights reserved. Short sections of text, not to exceed two paragraphs, may be quoted without explicit permission provided that full credit, including (C) notice, is given to the source. 
Can Employment Reduce Lawlessness and Rebellion? A Field Experiment with High-Risk Men in a Fragile State

Christopher Blattman and Jeannie Annan

NBER Working Paper No. 21289

June 2015

JEL No. C93,D74,J21,O12

\section{ABSTRACT}

States and aid agencies use employment programs to rehabilitate high-risk men in the belief that peaceful work opportunities will deter them from crime and violence. Rigorous evidence is rare. We experimentally evaluate a program of agricultural training, capital inputs, and counseling for Liberian ex-fighters who were illegally mining or occupying rubber plantations. 14 months after the program ended, men who accepted the program offer increased their farm employment and profits, and shifted work hours away from illicit activities. Men also reduced interest in mercenary work in a nearby war. Finally, some men did not receive their capital inputs but expected a future cash transfer instead, and they reduced illicit and mercenary activities most of all. The evidence suggests that illicit and mercenary labor supply responds to small changes in returns to peaceful work, especially future and ongoing incentives. But the impacts of training alone, without capital, appear to be low.

\section{Christopher Blattman}

School of International and Public Affairs

Columbia University

420 West 118th Street

New York, NY 10027

and NBER

chrisblattman@columbia.edu

Jeannie Annan

International Rescue Committee

New York, NY

jeannie.annan@gmail.com 


\section{Introduction}

After war, a common question is what to do with poor, unemployed, high-risk men such as ex-fighters. Poor job opportunities could mean they are easier to re-recruit into violence, increasing the risk that war recurs. ${ }^{1}$ They pose other risks as well. One is election violence. In Sierra Leone, for instance, parties paid ex-fighters to intimidate voters. ${ }^{2}$ Another is crime. Former paramilitaries in Colombia, for example, have been recruited by criminal bands. ${ }^{3}$ And, as this paper describes, ex-fighters in Liberia were drawn into illegal work and interest in mercenary fighting.

To prevent this, nearly every fragile state funds some form of public works scheme, training, or other employment intervention for young men. ${ }^{4}$ It is also the reason most demobilization, disarmament, and reintegration (DDR) programs have a heavy employment component. But can job programs turn swords into ploughshares?

These programs are rooted in three assumptions: first, that states can stimulate lawful employment by supplying training or capital; second, that lawful employment will decrease incentives for illegal work and rebellion; and third, that jobs and higher incomes will socially and politically integrate men into society.

The first assumption is plausible. Economic theory and evidence suggests that the average poor person has high returns to capital inputs and sometimes to skills, in large part because they are able but credit constrained. ${ }^{5}$ High-risk men in fragile states are not average, however. They have a comparative advantage in violence, and they often lack the human, social, and physical capital to succeed in peacetime labor markets.

Yet the evidence on such high-risk men is limited and inconclusive. Observational studies of DDR programs report low or indeterminate effects on economic and political reintegra-

\footnotetext{
${ }^{1}$ Walter (2004); Blattman and Ralston (2015)

${ }^{2}$ Christensen and Utas (2008)

${ }^{3}$ Nussio and Oppenheim (2014)

${ }^{4}$ e.g. World Bank (2012)

${ }^{5}$ See for instance Banerjee and Duflo (2011); Blattman and Ralston (2015).
} 
tion. ${ }^{6}$ By their own admission, however, most DDR programs are poorly executed. ${ }^{7}$ Also, often the primary goal of DDR is to get a peace agreement signed, not sustained economic reintegration.

The second assumption is rooted in the idea that fighters are rational and that crime and rebellionrespond to changes in the opportunity cost of participation (Becker, 1968; Popkin, 1979). While persuasive, there is little rigorous, individual-level evidence outside the United States (US). In developing countries, it comes mainly from country- and district-level analysis of income shocks. ${ }^{8}$ Similarly, in developed countries, studies also suggest city-level crime rates fall as wages rise. ${ }^{9}$ There are limits to testing theories of individual behavior with meso-level data, however, especially because income shocks also affect the incentives of rebel groups, states, and civilian populations. ${ }^{10}$

Some scholars also doubt that employment meaningfully deters crime and violence. Not all criminal activities crowd out work hours, and insurgent groups might not be labor constrained (Berman et al., 2011). While fighting is risky, sometimes being a civilian is riskier, and so many men join armed groups for the security they provide, especially in Liberia's wars (Bøås and Hatløy, 2008). Moreover, studies of gangs and revolutions suggest that the key motivator might not be wages but demand drivers such as status, ideology, outrage, or a desire for justice. For example, Levitt and Venkatesh (2000) argue for the symbolic value attached to seniority in US drug gangs. Scholars of revolution argue that injustices and other grievances generate outrage and with it an intrinsic satisfaction from violent action

\footnotetext{
${ }^{6}$ e.g. Humphreys and Weinstein, 2007; Levely, 2011. In Burundi, Gilligan et al. (2012) compare men in an unserved DDR region to men in two served regions, and see that men in the program region have greater incomes but see little evidence of socio-political integration.

${ }^{7}$ See for example Kingma and Muggah (2009); Tajima (2009).

${ }^{8}$ Weather and trade shocks intensify ongoing wars (e.g. Bazzi and Blattman, 2014; Miguel et al., 2004; Dube and Vargas, 2013) and municipal-level drug production in Mexico (Dube et al., 2014).

${ }^{9}$ See Freeman (1999). More recently, program evaluations show that residential job training programs reduce crime and poverty, but that these effects may be short-lived (Heckman and Kautz, 2013). The problem may be with the residential approach rather than the training itself.

${ }^{10}$ Income shocks could affect conflict and crime because they lower police/counterinsurgency capacity. Aggregate shocks may also affect armed recruitment strategies or incentives to pillage. Finally, weather shocks could incite conflict by inducing migration (such as pastoral people moving to settled lands) or increasing water struggles.
} 
(e.g. Merton, 1938; Gurr, 1971; Wood, 2003).

Finally, the third assumption, from employment and incomes to socio-political integration, is intuitively plausible but has no firm basis in theory or evidence. In principle, poverty could drive grievances or anomie that dissociate young men from mainstream society. Job programs could mend the damage. But evidence is limited. ${ }^{11}$

This paper evaluates a program that provided agricultural training and capital inputs to high-risk men in post-war Liberia. Liberia's war ended in 2003, but in 2009 thousands of ex-fighters still occupied rubber plantations, illicitly mined precious minerals, or illegally logged. They clustered in "hotspots" where the state had little control. The state considered them a major security risk.

To shift men away from illegal activities and mitigate mercenary recruitment, the nonprofit Action on Armed Violence (AoAV) designed a program including several months of residential agricultural training, counseling and "life skills" classes, and farm inputs worth \$125. AoAV recruited over 1100 high-risk men in 138 communities. Roughly half were randomly offered the program, and three-quarters complied.

Fourteen months after training, we observed several impacts. First, contrary to the conventional wisdom in DDR circles, even the highest risk men were overwhelmingly interested in farming. Second, treated men shifted their hours of work away from illicit resource extraction towards farming by roughly $20 \%$. Almost none exited illicit work completely, however. Rather they simply shifted their portfolio of occupations. Their incomes increased about $\$ 12$ a month as a result. Third, the program had little effect on peer networks, hierarchical military relationships, aggression, social integration, or attitudes toward violence or democracy.

Fourth, when an election crisis in Côte d'Ivoire led to a short war, between 3 and $10 \%$ of men in the control group reported actions such as attending secret meetings with recruiters

\footnotetext{
${ }^{11}$ One of the few employment interventions to measure these outcomes, a postwar cash transfer program in Uganda, finds large economic gains but little change in socio-political behavior (Blattman et al., 2014). Gilligan et al. (2012) reach similar conclusions with a DDR program in Burundi. More evidence is needed.
} 
or being willing to fight at the going recruitment fees. Many also reported talking to an excommander recently. We have several proxies for recruitment interest, most imperfect. None of our sample actually went to fight, since the war ended abruptly. Nonetheless, treated men were about a quarter less likely to report these mercenary recruitment proxies.

Finally, future economic incentives seem to have been crucial in deterring both illicit and mercenary interest. Roughly a third of treated men did not receive their package of farm inputs because of unexpected supply issues. At the time of the survey, AoAV had told these men to expect to receive a cash equivalent in the near future. Men would miss the transfer if they left their villages to fight abroad or mine, meaning the cash transfer was de facto conditional. We use arguably exogenous variation in the receipt of inputs (and the expectation of a future transfer) to show this incentive explains a large portion of the reduction in illicit mining and proxies for mercenary interest.

These results have several implications for the rehabilitation of high-risk men. For example, we see that high-risk men had positive returns to a supply-side intervention of agricultural capital and skills. This success contrasts with the spotty record of non-farm skills training, and suggests that agricultural DDR and jobs programs may be more effective in fragile agrarian states.

This increase in employment and incomes did not affect social and political integration, however, at least after 18 months. Thus economic assistance alone may be insufficient to fully reintegrate high-risk men. To our surprise, an intensive and well-executed attempt to socialize men through through counseling had little tangible effect in this case. We argue that some features of the program - its residential approach, concentrating ex-combatants with each other and with ex-commanders - interfered with effective resocialization.

Nonetheless, the higher returns to farming significantly changed incentives for crime and mercenary work. This is notable for several reasons: because rigorous individual-level evidence that crime and rebellion respond to legal wages is almost nonexistent; because so many other reintegration models and programs have failed; and finally because the specific 
labor response is insightful. A modest change in income (40 cents a day) led to a sizable shift in illicit employment, implying the labor supply between illegal and legal sectors is highly responsive to small changes in relative wages. Also note, however, that people do not exit illicit work entirely. Employment in both legal and criminal sectors is a rational response to risk, and so men optimally keep at least some of that alternative income stream in their portfolio of work. Grogger (1998) finds the same response among US criminals. This evidence suggests jobs programs are more likely to affect criminal activity on the intensive than extensive margin.

Finally, the importance of future payouts in deterring undesirable behavior implies that ongoing and conditional incentives may be an important element of peacebuilding. This implies that programs such as sustained cash-for-work could help deter crime or armed recruitment.

One caveat to these results is that all our outcomes are self-reported, and if the treated underreport crime or mercenary interest, we will overstate treatment effects. We argue this is unlikely given the pattern of outcomes we see, such as no treatment effect on the anti-social behaviors that were targeted by the program, and large effects on behaviors ignored in the curriculum (such as illicit mining). Also, we discuss evidence from urban Liberia that high risk men in the control group may underreport crime. But systematic misreporting is a risk, most of all with our proxies for mercenary interest and activity.

A second caveat is that it is difficult to say why the program made men less likely to commit crimes or rebel. This is a recurring limitation of quantitative studies of rebellion: we cannot measure motivations.

Nonetheless, the patterns of results suggest that this particular program deterred mercenary interest in large part because of its effects on material incentives. Not only does the effect of the intervention on mercenary interest resemble the effect on illegal work, but both are especially influenced by future cash incentives. We also did not see an effect on armed social networks, attitudes to violence, or non-material forms of aggression, suggesting the 
program didn't work by breaking recruitment networks or socializing men against violence. ${ }^{12}$ We cannot exclude a role for non-material incentives in recruitment. For example, training and farming may have strengthened the social standing of treated men and made agrarian life more attractive. While undoubtedly true to some extent, this interpretation is hard to square with the deterrence effect of future cash transfers, or with the fact that most of our measures of community integration were unaffected by the program. In any case, our interpretation is merely that material incentives do matter to ex-fighters, at least on the margin.

The remainder of this paper outlines the program and experimental protocols, the data we collected, a theoretical framework for understanding program components, the impacts of the program, and a discussion of how we can interpret the impacts to speak to theoretical and policy debates on recidivism and violence prevention.

\section{Intervention and experiment}

From 1989-96 and 1999-2003 two civil wars wracked Liberia. They killed nearly 10\% of Liberia's 3.5 million people, displaced a majority, and recruited tens of thousands of young men into combat (Republic of Liberia, 2008). Since 2003, however, Liberia has been at peace and growing economically.

By 2008, the government and a United Nations (UN) peacekeeping force estimated 9,000 ex-fighters were living in remote "hotspots" were engaged in illegal resource extraction, including alluvial gold and diamond mining, logging, and rubber tapping (Republic of Liberia, 2008). The government was eager to curb resource theft so that the concessions could be licensed and taxed, typically to foreign firms. These were crucial sectors for the Liberian economy, and ending illegal exploitation was one of the government's core economic recovery strategies.

\footnotetext{
${ }^{12}$ Note that, while breaking networks is usually an objective of DDR programs, it was not AoAV's explicit objective or a basis for program design.
} 
Peacekeepers also viewed these hotspot men as threats to regional peace. For decades, regional conflicts have been fueled by cross-border mercenary recruitment of men like these. A 2008 coup in neighboring Guinea fueled rumors of recruitment of Liberians as mercenaries, and there were regular violent clashes between the state and plantation squatters.

\section{$2.1 \quad$ The program}

As a result, one of the highest priorities was to create stable jobs for high-risk men. To do so, AoAV rebuilt and operated two training centers, one in central Bong County, and one in the eastern Sinoe County. They designed a program with four main components:

1. Residential coursework and practical training in rice and vegetable farming, animal husbandry, rubber and palm cultivation (three months in Sinoe and four months in Bong). In residence, AoAV also provided meals, lodging, clothing, literacy classes, and basic medical care and personal items.

2. Counseling and a "life skills" class that aimed to socialize men to peacetime life. During the residential program it met three times a week in groups of 20. The locally-developed approach used semi-scripted lectures and group discussion, and was led by facilitators who were ex-combatants themselves. It focused on: reframing and understanding wartime actions; dealing with symptoms of traumatic stress; managing anger; and resolving disputes peacefully. Facilitators also conducted informal out-of-classroom mentoring.

3. After graduation, transport to a community of their choice, coordinating with the community for access to farmland.

4. A two-stage package of tools/supplies tailored to the trainee's interests, such as vegetable farming or animal husbandry, that cost $\$ 125$. Men received the first half upon graduation and the second half several weeks later, if AoAV could locate them and 
confirm they had initiated farming or animal-raising. In addition, Sinoe graduates were given $\$ 50$ cash. This was not part of the program plan but was negotiated after a miscommunication during recruitment.

AoAV estimated the cost (excluding fixed costs such as training site construction and head office expenses) to be roughly $\$ 1275$ per person in $2009 .^{13}$

The government and UN peacekeeping force used the exit of ex-combatants from the enclaves to increase state control of the area, which typically meant a civilian administrator, periodic UN peacekeeper patrols, and the preparations to sell mining or rubber tapping licenses to small and medium firms. With virtually no police or staff, however, the state's reach was limited. The main change on the ground was likely the slow transfer of the concessions to private companies.

\subsection{Target sites}

For the Sinoe site, AoAV recruited in 35 communities on and around the Sinoe Rubber Plantation. A few months before, it had reverted to state control after the expulsion of a former rebel general. Hundreds of squatters, mainly non-ranking ex-fighters and their families, still remained.

For the Bong program, AoAV recruited in 103 communities in three regions. First, several dozen remote villages and mining camps in Gbarpolu County-one of the most isolated counties, known for illicit logging and mining. The camps were magnets for opportunistic youth and ex-fighters, some led by ex-commanders. Second, they recruited in 12 villages and towns in and around Ganta, a border city, where at the time there were reports of mercenary recruitment after a Guinean coup. Third, they recruited ex-combatants from villages near the training site.

\footnotetext{
${ }^{13}$ Appendix A describes the curriculum and budget.
} 
Figure 1: Sample recruitment, selection, randomization, and data collection

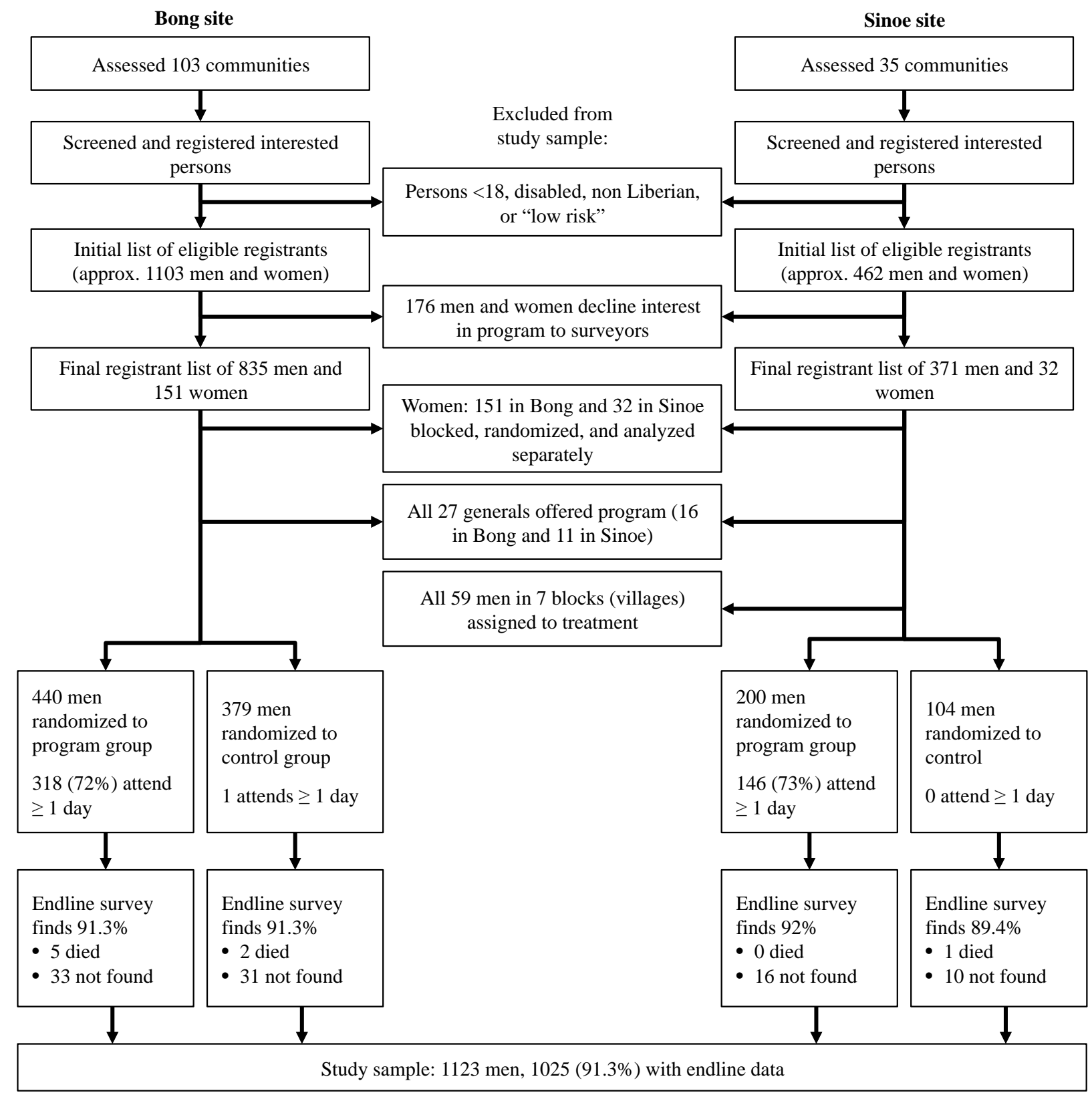

\subsection{Recruitment}

The Bong training site accommodated 350 men and 50 women, while the Sinoe site accommodated 175 men and 25 women. We worked with AoAV to assign offers to the program randomly among screened, registered men. Figure 1 illustrates sample recruitment, selection, 
randomization, and data.

From May to October 2009 AoAV advertised the program in community meetings, and screened and registered interested and eligible people. There was overwhelming interest in the program among the hotspot population, high-risk or not. AoAV collected extensive data on war experiences and current economic activities and attempted to register those they deemed to be the highest-risk men, especially those least served by previous postwar programs. They excluded people deemed physically incapable of agriculture and non-Liberians.

We have no data on the men screened out, but we observed the process first-hand and observed mainly low-risk men being turned away (e.g. non-combatants, or well integrated ex-fighters). Undoubtedly some high-risk men were not interested in the program, so did not register.

AoAV registered 1,565 men and women and passed them to a baseline survey team. 176 people withdrew their interest or could not be found, resulting in 1,206 registered men and 183 women. Our experimental analysis excludes 27 high-ranking "generals" who were automatically offered the program, as the UN considered it too risky to exclude them. We also exclude women who participated in the program, who were few in number have very different characteristics and risks.

This screening and self-selection has implications for the interpretation of treatment effects: they apply to the subset of non-ranking, high-risk men who have some minimum interest in a training intervention. This is probably the main quantity of academic and policy interest, however.

\subsection{Randomization}

To randomize men, we blocked by training site, rank, and community and, within blocks, assigned each person a uniform random variable and sorted in ascending order. Men were randomly assigned to an offer to enter the program in this order within blocks until a target number per block was reached. If a person refused or could not be located, they were still 
assigned to the treatment group (an offer) and the offer went to the next person on the list. ${ }^{14}$

Of 1,123 men, $57 \%$ were assigned to treatment.

\section{Data}

Table 1 describes men at baseline. ${ }^{15}$ On average, the men were aged 30, had 5.9 years of schooling, with $27 \%$ literate. They reported cash earnings of $\$ 47$ in the past month, savings of $\$ 46$, and debts of $\$ 7.74 \%$ were in a wartime faction, though only $17 \%$ reported being on the front lines. $13 \%$ reported close relations with a former commander.

Most men already were already subsistence farming, as markets were distant and food expensive. On average they had 4.8 years of farm experience. $32 \%$ said farming was their main source of income, and 29\% reported it was non-farm labor or business. $47 \%$ reported some work in illicit activities in the past week, but only $23 \%$ said that this was their main source of income. $87 \%$ said they were "very interested" in being a farmer. $90 \%$ said they could easily access 10 acres of land.

The sample was broadly balanced along covariates. Columns 2 and 3 of Table 1 report the treatment and control group difference in select baseline covariates. Just $7 \%$ of all covariates have an imbalance with $p<.1$. The treatment group, however, had lower savings and spent more time in armed factions. ${ }^{16}$ All treatment estimates control for all covariates.

\footnotetext{
${ }^{14}$ We adopted this method because AoAV had a fixed number of program spots to fill and a short time in which to inform and pick up the dispersed men. In Sinoe, 59 men from 7 blocks were dropped from the study because their block was fully assigned to treatment. Bridge collapses and construction delays meant that they received only one or two days notice before pickup, thereby increasing refusal rates such that all men received the offer.

${ }^{15}$ See Appendix B.1 for more covariates. Surveyors failed to collect data on $13(1.2 \%)$ men. $5 \%$ also opted to skip some sensitive questions on war experiences. We impute the median for missing baseline data.

${ }^{16} \mathrm{~A}$ joint test of significance of all 83 baseline covariates has $p=.41$ excluding these two covariates, but $p<.01$. including them. Note, however, that other variables related to wealth, debts, armed group activity, and violence have little association with treatment. Moreover, there is little treatment-control difference in predicted outcomes using baseline covariates (see Appendix B.1). As a result, imbalance is unlikely to be an identification concern.
} 
Table 1: Baseline summary statistics and test of randomization balance

\begin{tabular}{lccc}
\hline & & Test of balance $(\mathrm{n}=1025)$ \\
\cline { 2 - 4 } & Control & Treatment & \\
Baseline covariate & mean & difference & p-value \\
& $(1)$ & $(2)$ & $(3)$ \\
\hline Age & 30.5 & -0.617 & 0.256 \\
Lives with spouse/partner & .722 & -0.035 & 0.215 \\
Number of children & 2.5 & -0.207 & 0.148 \\
Disabled, injured, or ill & .349 & -0.011 & 0.664 \\
Years of schooling & 5.68 & 0.210 & 0.364 \\
Said would attend if selected & .984 & 0.002 & 0.616 \\
Durable assets index (z-score) & -0.04 & -0.006 & 0.909 \\
Stock of savings (USD) & 44.2 & -13.066 & 0.025 \\
Debt stock (USD) & 7.2 & -0.573 & 0.587 \\
Agricultural experience index (z-score) & 0.09 & -0.062 & 0.390 \\
Aggressive behaviors index (0-12) & 1.18 & 0.125 & 0.248 \\
Main income: Illicit resources & .228 & 0.001 & 0.955 \\
Main income: Legal nonfarm work & .292 & -0.029 & 0.362 \\
Very interested in farming & .863 & -0.012 & 0.561 \\
Can access 10 acres farmland & 0.90 & 0.03 & 0.21 \\
Ex-combatant & .727 & -0.006 & 0.826 \\
Months in a faction & 23.8 & 5.731 & 0.002 \\
Ex-commander relations index (z-score) & 0.04 & -0.085 & 0.171 \\
Patience index (0-4) & 2.97 & 0.010 & 0.878 \\
Risk affinity index (0-3) & 0.33 & 0.037 & 0.370 \\
\hline
\end{tabular}

Notes: Columns (2) and (3) report results of an OLS regression of each covariate on the treatment indicator and block fixed effects. Standard errors are clustered by village. USD variables are censored at the 99th percentile.

Endline surveys and attrition. We conducted endline surveys from February to June 2011, 18 months after baseline and 14 months after training. The sample was mobile and difficult to track, but we nonetheless surveyed 1025 (91.3\%) of 1,123 men. ${ }^{17}$ Many had multiple aliases. Roughly $45 \%$ moved between surveys, many changing locations every few months. Few had mobile phones. We invested heavily in tracking out of concern that the

\footnotetext{
${ }^{17}$ Nine had died and the remainder could not be found. Roughly two-thirds of the sample was found in the first 10 weeks. The remaining third took three months to track. To reduce bias from the timing of their survey, we first tracked a random half of the unfound, adding the second half after two months (see Appendix B.2).
} 
hardest to find would be the most prone to violence. We made at least four attempts to locate each person. To mitigate excess attrition among the untreated, they received a phone worth $\$ 15$ for completing the endline.

Attrition is not significantly correlated with treatment, and all baseline covariates explain just 11 percent of the variation. Some covariates are significantly related, and imply unfound could be those with a higher propensity for illicit activities and violence - they are slightly more likely to be ex-combatants, have slightly higher baseline aggression, and have been illicit rubber tappers. ${ }^{18}$

Qualitative data. We also conducted eight weeks of unstructured interviews before, during, and after the program with participants, community leaders, UN and government personnel, and non-study residents. Furthermore, under our supervision, one American and two Liberian research assistants followed 26 treated men over two years, typically interviewing them four times (before, during and twice after training). ${ }^{19}$ To understand recruitment activities we also conducted informal interviews with ex-fighters and ex-commanders outside our sample, as well as government and UN personnel, during the crisis in Côte d'Ivoire.

\section{Conceptual framework}

AoAV designed their intervention to affect occupational choice in three ways. First, they used training to raise the returns to labor and capital in agriculture. Second, the input package aimed to relieve a constraint on available capital, with inputs that were difficult to sell or use in other sectors. Like many DDR and correctional programs, the goal was to provide material incentives for lawful rather than unlawful work.

A third aspect of the intervention, the counseling and life-skills, aimed at something

\footnotetext{
${ }^{18}$ See Appendix B.3 for regression results. A test of joint significance of all covariates, however, has $p<.01$.

${ }^{19}$ They followed semi-structured questionnaires at each stage, with topics including: program experiences, economic activities, social relationships, war experiences, aggression, and aspirations. In addition to interviews, research assistants accompanied these individuals to class, to their fieldwork, mealtimes, and free time. They took detailed notes and recorded and transcribed interviews.
} 
less conventional: socialization. The idea was that some actions or professions have direct utility benefits or penalties - that people have preferences over how their income is earned (e.g. Akerlof and Kranton, 2000). These preferences are thought to be partly rooted in one's self-image, social category, and experiences. By providing education, a new profession, and relocation, AoAV's intervention tried to affect occupational choice by changing self-image and peers, and thus affecting penalties from oneself or peers for deviant behavior.

This section tries to capture these aims in a simple model of occupational choice between legal and illegal occupations. We outline the framework and key insights here, with full details in Appendix C.

\subsection{Setup}

We assume people allocate their labor between leisure $l$, legal activities $L^{a}$ (such as agriculture), and illicit activities $L^{m}$ (such as unlicensed mining or mercenary work). Legal work ("agriculture", for simplicity) is a function of one's labor, productivity $\theta$ (driven by locallyavailable technologies and techniques), and capital inputs $X_{t-1}$ (such as seeds), which are decided in the previous period. Agricultural output is thus $F\left(\theta, L_{t}^{a}, X_{t-1}\right)$, and AoAV's intervention provides inputs and aims to increase productivity.

Meanwhile, we assume mining and mercenary work pays an hourly wage that varies over time, $w_{t} \cdot{ }^{20}$ It also comes with a risk of future punishment. For simplicity, we assume this cost is a linear function of last periods' hours in mining and mercenary work: $\rho f L_{t-1}^{m}$, where $\rho$ is the probability of apprehension and $f$ is the punishment. Punishment includes imprisonment and foregone wages, but it could also include the withholding of a "peace dividend" such as a cash transfer. ${ }^{21}$

\footnotetext{
${ }^{20}$ In other words, crime principally uses labor as an input. For example, mining requires capital and land rights, and the "bosses" who hold these hire men as "mining boys" on short-term renewable contracts that pay a daily wage plus a payment tied to output. While there is uncertainty in output, and hence the wage, output is principally a function of labor inputs by the laborer (given a boss' capital).

${ }^{21}$ As described below, treated men who chose to specialize in animal-raising expected to receive an in-kind capital or cash transfer. In this case, $\rho$ is the possibility of missing the transfer if he leaves town to mine or fight, and $f$ the value of the transfer. In principle $f$ could include risk of injury or death, except we've modeled it as a transitory shock. Nonetheless a very large $f$ would provide the basic comparative statics.
} 
Total earnings from all activities are thus $y_{t} \equiv p_{t} F\left(\theta, L_{t}^{a}, X_{t-1}\right)+w_{t} L_{t}^{m}-\rho f L_{t-1}^{m}$, where $p$ is the price for output. In addition to investing in agricultural inputs, the person can also invest or borrow through a riskless asset with constant returns $1+r .{ }^{22}$ We can consider the case where there is no production risk, and also the case where agricultural productivity and the illicit wage are subject to stochastic shocks.

Finally, we assume people have the utility function $U\left(c, l, \sigma L^{m}\right)$. This includes the standard preferences over consumption $c$ and leisure, but it also includes the possibility of direct utility benefits or penalties from the type of work through the term $\sigma L^{m} \cdot{ }^{23}$ If people are socialized to penalize themselves for illicit work, then $\sigma<0$ and $U_{\sigma L^{m}}^{\prime} \leq 0$. We could also interpret $\sigma<0$ as external social sanctions or disapproval. In principle, however, there is no reason $\sigma$ has to be negative. To the extent that a personal experience or identity-related injustice creates a grievance or a sense of anomie, then $\sigma>0$ and $U_{\sigma L^{m}}^{\prime}>0$. This corresponds to the case where rebellious or illicit activity delivers positive utility benefits, perhaps because it is rewarded with esteem and respect, or because it satisfies some preference for justice or revenge. ${ }^{24}$ In either case, the program's aim to socialize and normalize high-risk men can be captured crudely in this framework as a decrease in $\sigma$.

The setup resembles a classic occupational choice of crime model, except with home production and the potential for (dis)utility over illicit labor. People choose their labor allocations, consumption, and inputs for next period's production in order to maximize the present value of expected utility, subject to a simple budget constraint (see Appendix C)

\footnotetext{
${ }^{22}$ In each period $t$, the person decides how much to invest for next period $a_{t+1}$ and reaps interests $r a_{t}$ from last period's investments.

${ }^{23}$ We include this $\sigma$ preference term in the utility function to distinguish it from the material disincentives included in expected earnings (the risk of punishment). Consumption is equal to earnings plus interest on the risk-free asset, less investment in farm inputs and the risk-free asset).

${ }^{24}$ For example, Wood (2003) suggests that El Salvadorian insurgents derived "pleasure in agency" following government injustices.
} 


\subsection{Insights from the model}

Solving out the model provides a number of insights. First, for AoAV's training or inputs to affect production decisions (and deter illicit work) specific market failures must exist. In particular, the provision of training and capital will only shift employment patterns if credit markets function poorly or agricultural knowledge is imperfect, and hence the men are below their efficient scale of agriculture. Otherwise the men would be able to access the needed technology and borrow to finance any training and inputs until they reach efficient scale, and new in-kind inputs would be liquidated or divested.

These assumptions seem reasonable in rural Liberia where credit and insurance are almost non-existent and agricultural technology is rudimentary. But success also requires that men have high returns to these skills and capital once the program relieves these constraints. In particular, men cannot be bound by some other constraint, such as inadequate insurance or insecure property rights.

Second, the model illustrates why men are unlikely to exit illicit activities entirely. If there are high but diminishing returns to agriculture, then people will optimally engage in both agriculture and illicit activities, allocating their time so that the net marginal product of labor in agriculture equals that in illicit work. This is even more the case when there is risk aversion and uncertainty, since men have additional an incentive to perform both activities to reduce risk. Thus the model predicts that increasing agricultural productivity alone will reduce the proportion of hours than are illicit, but not necessarily the incidence of any illicit work.

Punishments, however, can encourage exit. Increasing the risk of being caught, or the penalties once caught, are one way to do so (and may not be subject to the same diminishing returns). This is the common rationale for policing and punishment. There are other ways to penalize crime, such as withdrawing a benefit. For instance, a capital transfer program conditional on no arrests, or living away from lootable resources, could have similar effects. As we discuss below, at endline a subset of the men were awaiting a cash transfer from 
AoAV, and we will argue this punishment lens is a useful way to consider their incentives.

Finally, the model suggests who ought to be targeted by agriculture-oriented reintegration program, in terms of who is more likely to engage in illicit activities but potential to be influenced by policy: people with low initial productivity but interest in learning (in agriculture, in this case, though the same argument could be made for other peaceful activities); and who have little capital and are credit constrained.

Also, the model points out that it will be more difficult to persuade men to pick up agriculture when their disutility of illicit work is low, when the returns to illicit work are high (such as rising gold prices), and when agricultural input prices are relatively high.

\section{$5 \quad$ Empirical strategy}

We estimate the simple intent to treat (ITT) effect via an ordinary least squares (OLS) regression of the outcome on an indicator for receiving an offer to enter the program, controlling for all baseline covariates. ${ }^{25}$ Because we are testing multiple outcomes, we also test whether an additive standardized treatment effect of measures in "families" of outcomes is different from zero. ${ }^{26}$ We cluster standard errors by baseline village.

We report every outcome measured in the endline survey, save a small number of secondary outcomes that we report in the appendix. ${ }^{27}$ The main outcomes of interest were defined by the stated aims of the intervention and our theoretical framework, and are fairly commonsensical: agricultural skills acquired and used; employment in legal and illicit activities; income; anti-social behaviors and other participation in/attitudes toward violence; risk of re-recruitment into armed groups and other violent organizations; and social and community integration. ${ }^{28}$

\footnotetext{
${ }^{25}$ To reduce sensitivity to outliers, we top-code all continuous variables at the 99th percentile. Appendix B.5 discusses the potential for within-village spillover effects. In brief, spillovers are unlikely because the sample was a typically under $5 \%$ of the village population and agricultural production.

${ }^{26}$ In general, these families were pre-defined by virtue of belonging to the same survey sub-section.

${ }^{27}$ See Appendix D.2. These include educational investments, drug and alcohol use, risky sex, commission of domestic abuse, and mental health.

${ }^{28}$ The experiment was not pre-registered as registration was unusual (and indeed a social science registry
} 
Accounting for imperfect compliance $74 \%$ of those assigned to treatment complied, in that they attended at least a day. $94 \%$ of those who attended a day graduated. The rest quit early or were dismissed for infractions. To estimate the effect of the program on compliers, we also estimate the effect of treatment on the treated (TOT) using assignment to an offer as an instrument for attending at least a day.

Non-compliance was fairly unsystematic. Qualitatively, people said they did not attend largely because a few days was inadequate notice. Others mentioned family obligations, debts, illness, or jobs that would not permit them to return if absent. In an OLS regression of compliance on baseline covariates, the $R^{2}$ statistic is just 0.06 and most of covariates are unrelated to compliance. ${ }^{29}$

Identifying the marginal impact of capital inputs. Graduates mainly selected packages for vegetable farming $(60 \%)$ and pig and poultry husbandry (29\%). Roughly half of graduates, however, report that they did not receive the full package. This includes all who chose pigs and poultry, because of external supply problems. Chicks and piglets were not available in Liberia and AoAV had to transport them in from Guinea. Despite repeated attempts, the animals did not survive the journey and were never distributed. This meant that some program graduates returned to their communities and received seeds and other farm inputs, but others in the same communities received materials to build a pig sty or chicken coop but not the animals.

Some months before the endline survey, AoAV announced that they would give a $\$ 100$ cash grant to the men who chose animals, though they gave no specific date. We ran the did not exist) at the time of the study. The specific outbreak of the violence in Côte d'Ivoire was unexpected, and the questions were hurriedly developed for that purpose, but the general aim of reducing risk of recruitment was fundamental to the intervention's aims and design. At baseline and endline risk of recruitment was also assessed via the nature of relationships with other ex-combatants and ex-commanders, since the "breaking of armed group linkages" is a common aim of reintegration programs. The items reported in the appendix are secondary in the sense that they were not theorized by either the program (in its official aims and design) or by our core theory, but nonetheless they could easily be byproducts of the training program and socialization, or of economic success.

${ }^{29}$ Compliance is slightly but significantly increasing in savings stocks and length of time in a faction, and falling in debts. An F-test of all covariates, however, has p $<.01$. See Appendix B.4 for details. 
endline survey shortly before disbursal.

We can use this supply interruption to compare the impacts of receiving training and inputs versus training and a promise of a cash transfer in the near future. While the interruption was exogenous, men's choice of animal versus farm input packages was not. We can interpret any difference as causal if we think selection of package is exogenous conditional on observed data.

Conditional unconfoundedness is plausible. Animals have lower cash flow than vegetables, are more capital intensive, involve less labor, and are perceived to be more profitable. Thus we might expect more patient, wealthier men with other labor opportunities to choose animals. But we see no such pattern; the choice of specializations seems to be relatively uncorrelated with a rich set of baseline covariates. Table 2 report an OLS regression of poultry/pig package choice on select baseline covariates among graduates. Only one covariate is significant: a $1 \mathrm{SD}$ increase in agricultural experience is associated with a 7 percentage point increase in poultry/pig choice. 
Table 2: Correlates of package selection

\begin{tabular}{|c|c|c|}
\hline \multirow[b]{2}{*}{ Baseline covariate } & \multicolumn{2}{|c|}{$\begin{array}{c}\text { Chose poultry or pigs (if } \\
\text { graduated) }\end{array}$} \\
\hline & Coeff. & Std. Err. \\
\hline Age & -0.007 & {$[.005]$} \\
\hline Lives with spouse/partner & 0.070 & {$[.062]$} \\
\hline Number of children & -0.022 & {$[.015]$} \\
\hline Disabled, injured, or ill & -0.051 & {$[.053]$} \\
\hline Years of schooling & 0.008 & {$[.007]$} \\
\hline Said would attend if selected & 0.165 & {$[.380]$} \\
\hline Durable assets (z-score) & 0.012 & {$[.028]$} \\
\hline Stock of savings (USD) & 0.000 & {$[0000]$} \\
\hline Debt stock (USD) & 0.001 & {$[.002]$} \\
\hline Agricultural experience (z-score) & 0.070 & {$[.034]^{* *}$} \\
\hline Aggressive behaviors (0-12) & -0.004 & {$[.013]$} \\
\hline Main income: Illicit resources & 0.081 & {$[.059]$} \\
\hline Main income: Nonfarm work & 0.036 & {$[.056]$} \\
\hline Very interested in farming & 0.007 & {$[.082]$} \\
\hline Ex-combatant & -0.068 & {$[.066]$} \\
\hline Months in a faction & 0.000 & {$[.001]$} \\
\hline Ex-commander relations (z-score) & 0.023 & {$[.027]$} \\
\hline Patience index $(0-4)$ & 0.003 & {$[.024]$} \\
\hline Risk affinity index (0-3) & -0.028 & {$[.046]$} \\
\hline Observations & \multicolumn{2}{|c|}{407} \\
\hline Dependent variable mean & \multicolumn{2}{|c|}{0.295} \\
\hline R-squared & \multicolumn{2}{|c|}{0.10} \\
\hline
\end{tabular}

\section{$6 \quad$ Results}

Training ran November 2009 to February 2010 in Bong, and September to December 2009 in Sinoe. Based on our observations, classroom instruction was practical and pitched at an appropriate level. Instruction involved substantial field training with animals and crops. Students learned techniques appropriate for small-scale cash cropping and animal husbandry unavailable before, such as seed germination or fertilizer, pesticide, and vaccine use.

Fights, angry protests, strikes, and the threat of violence were weekly occurrences on the 
training sites. While the events were disruptive, they were also opportunities for the students to learn to work out grievances peacefully and apply lessons from the life skills class.

Overall, students were enthusiastic about the life skills and counseling. In interviews a year later, they frequently brought up slogans and examples from the class, and its impact on their lives. In the endline survey, when asked what part of the program most changed their life, $23 \%$ of graduates said the life skills curriculum and 19\% said counseling, compared to $44 \%$ who said skills training and $3 \%$ who said inputs.

More than half of graduates chose to return to their baseline community, and most others chose a community in the same county. Across Liberia farmland is plentiful and arranging for a few acres of land was straightforward. Community members often said they were proud of their new or returned residents.

Graduates faced steep challenges, however. They typically returned to remote communities with sizable local markets but difficult road access and limited access to external markets and inputs. Furthermore, graduates reported serious liquidity constraints, and hence little access to tools and inputs beyond what AoAV provided. Farmland was plentiful but typically rugged, semi-cleared rainforest. Liberian farmers seldom have access to plows, draft animals, or tractors and perform most work by hand. Pests and rainfall are also persistent challenges. Program impacts need to be considered in light of these difficulties.

\subsection{Impacts on occupational choice and incomes}

Table 3 reports control group means and treatment effects for economic outcomes. We focus on TOT estimates. Men typically had a portfolio of occupations. Illicit opportunities were often distant from village settlements, and so it was common for men to farm some weeks of the year in their base village, leave for petty trading, then move elsewhere to mine, $\log$ or tap rubber for a period. Changes in occupation often meant spending fewer days in "the bush" illicitly mining, and more days in town farming or trading.

The program led to large increases in agricultural work. $61 \%$ of controls said they were 
engaged in farming or animal-raising, and this increased 15.5 percentage points among the treated - a $26 \%$ rise relative to controls. Treated men also expressed more interest in agriculture as a career. Interest in farming was high even without treatment: $95 \%$ of controls said that they could make a good living farming, 78\% were interested in farming in future, and $90 \%$ were interested in raising animals. Treated men were no more likely to think that farming is a good career (since opinion is nearly unanimous) but they were 12 percentage points more likely to express interest in farming. Hours worked in agriculture increased by 4 hours per week, or $33 \%$ relative to controls. ${ }^{30}$

We also observed a shift on the intensive margin away from illicit resource extraction. We collected days and hours worked at 15 activities in the previous month (a time of dry season farming and crop sales). Controls reported 49 hours of work per week, and total hours were not affected by treatment. But treated men decreased hours of resource extraction by 3.7 $(23 \%)$ and increased other work by 5 hours, mainly agriculture. Importantly, the treated did not exit illicit activities completely $-40 \%$ of control men engaged in any illicit extraction and this was only 3.2 percentage points lower among the treated, not statistically significant.

Reports of felony crime were rare and perhaps for this reason we saw little effect of treatment. We asked about drug selling and theft (stealing, pickpocketing, and armed robbery) which we assembled into a standardized index. Only $2 \%$ of control men reported drug selling (usually marijuana) and only about $2 \%$ of men reported thievery. ${ }^{31}$ Treated men were half as likely to report they sold drugs, not statistically significant. There was little effect of treatment on self-reported stealing.

\footnotetext{
${ }^{30}$ Treated men were also farming 2 more acres (48\%) than controls, though this was not statistically significant. Appendix D.1 examines individual farm activities. Treated men were more than twice as likely to be using improved techniques, such as growing seedlings, and were $43 \%$ more likely to have sold crops.

${ }^{31}$ See Appendix D.1 for a breakdown of the index.
} 
Table 3: Program impacts on occupational choice and income

\begin{tabular}{|c|c|c|c|c|c|}
\hline \multirow[b]{3}{*}{ Outcome } & \multirow{3}{*}{$\begin{array}{c}\text { Control } \\
\text { Mean } \\
(1)\end{array}$} & \multicolumn{4}{|c|}{ Treatment effect estimates $(\mathrm{n}=1025)$} \\
\hline & & \multicolumn{2}{|c|}{ ITT } & \multicolumn{2}{|c|}{ TOT } \\
\hline & & $\begin{array}{c}\text { Coeff. } \\
(2)\end{array}$ & $\begin{array}{l}\text { Std. Err. } \\
\text { (3) }\end{array}$ & $\begin{array}{c}\text { Coeff. } \\
(4)\end{array}$ & $\begin{array}{l}\text { Std. Err. } \\
\text { (5) }\end{array}$ \\
\hline \multicolumn{6}{|l|}{ Agricultural engagement: } \\
\hline Raising crops/animals $\dagger$ & 0.61 & 0.118 & {$[0.030]^{* * *}$} & 0.155 & {$[0.036]^{* * *}$} \\
\hline Acres under cultivation & 4.43 & 1.556 & {$[2.146]$} & 2.037 & {$[2.573]$} \\
\hline Thinks farming is a good living & 0.95 & 0.008 & {$[0.016]$} & 0.010 & {$[0.019]$} \\
\hline Interested in farming & 0.78 & 0.090 & {$[0.029]^{* * *}$} & 0.118 & {$[0.035]^{* * *}$} \\
\hline Interested in raising animals & 0.90 & 0.049 & {$[0.019]^{* *}$} & 0.064 & {$[0.023]^{* * *}$} \\
\hline Hours worked/week, past month & 49.33 & 0.978 & {$[2.357]$} & 1.278 & {$[2.824]$} \\
\hline Illicit resource extraction & 15.57 & -2.829 & {$[1.350]^{* *}$} & -3.697 & {$[1.593]^{* *}$} \\
\hline Logging & 2.79 & -0.926 & {$[0.649]$} & -1.210 & {$[0.773]$} \\
\hline Mining & 10.53 & -1.356 & {$[1.140]$} & -1.772 & {$[1.362]$} \\
\hline Rubber tapping & 2.25 & -0.547 & {$[0.573]$} & -0.715 & [0.682] \\
\hline Farming and animal-raising & 11.91 & 3.131 & {$[1.180]^{* * *}$} & 4.090 & {$[1.415]^{* * *}$} \\
\hline Farming & 10.45 & 2.620 & {$[1.037]^{* *}$} & 3.423 & {$[1.242]^{* * *}$} \\
\hline Animal-raising & 1.46 & 0.511 & {$[0.508]$} & 0.667 & [0.609] \\
\hline Contract agricultural labor & 1.82 & -0.116 & {$[0.320]$} & -0.152 & {$[0.383]$} \\
\hline Palm, coconut, sugar cutting & 0.34 & 0.264 & {$[0.343]$} & 0.345 & {$[0.413]$} \\
\hline Hunting & 1.18 & 0.215 & {$[0.334]$} & 0.281 & {$[0.401]$} \\
\hline Non-farm labor and business & 18.16 & -0.170 & {$[2.055]$} & -0.222 & {$[2.464]$} \\
\hline Other activities & 0.36 & 0.483 & {$[0.571]$} & 0.632 & {$[0.682]$} \\
\hline \multicolumn{6}{|l|}{ Other illicit activities: } \\
\hline Any illicit resource extraction & 0.40 & -0.025 & {$[0.032]$} & -0.032 & {$[0.038]$} \\
\hline Sells any soft or hard drugs & 0.02 & -0.008 & {$[0.011]$} & -0.010 & {$[0.013]$} \\
\hline Stealing activities (z-score) $\dagger$ & -0.05 & 0.046 & {$[0.064]$} & 0.060 & {$[0.077]$} \\
\hline Income index (z-score) & -0.08 & 0.120 & {$[0.059]^{* *}$} & 0.157 & {$[0.071]^{* *}$} \\
\hline Cash earnings, past month (USD) & 95.13 & 9.076 & {$[9.555]$} & 11.820 & [11.398] \\
\hline Durable assets (z-score) & -0.11 & 0.122 & {$[0.059]^{* *}$} & 0.160 & {$[0.071]^{* *}$} \\
\hline
\end{tabular}

Notes: Columns (2) and (3) report the intent-to-treat (ITT) estimate, and columns (4) and (5) estimate the effect of treatment on the treated (TOT) via two-stage least squares. All regressions include block dummies and baseline covariates. Standard errors are clustered at the village level.

$\dagger$ See Appendix D.1 for all index components.

*** $\mathrm{p}<0.01,{ }^{* *} \mathrm{p}<0.05,{ }^{*} \mathrm{p}<0.1$

Incomes rose as a result. We measured income by combining two measures, which together increased .16 standard deviations. First, we asked each respondent his net cash earn- 
ings in the past four weeks, activity by activity. ${ }^{32}$ This earnings measure may be subject to recall and other biases, and does not capture home production. Also, agricultural incomes may not have been earned in the past month. We approximate a measure of permanent income using durable assets - a standardized index constructed by taking the first principal component of 42 measures of land, housing quality, and durable household assets.

Controls reported $\$ 95$ in earnings in the month prior to the survey, and this was $\$ 11.82$ higher among treated men, a 12\% increase (not significant, in part because of high variance). Treated men also reported a 0.16 standard deviation increase in the durable assets index, significant at the $5 \%$ level. The family index of both is statistically significant. This durable asset increase is likely a result of previous harvests (of which there were 2-3 since the end of the training program), and is probably a more reliable guide to income than earnings.

In general, these results are robust to alternate treatment effects specifications and attrition bounds (see Appendix D.3).

Returns. In the simplest case, we imagine the $\$ 11.82$ earnings treatment effect represents a permanent increase in monthly income $\$ 141$ annually. This is $11 \%$ of the per person program cost of $\$ 1275$, and is the cost of capital at which a $\$ 141$ perpetuity breaks even. This is not an especially high or rapid private return. Moderate social externalities, however, could make it a more promising social investment. In this case, the intervention allowed the government to reclaim resource concessions and, as we see next, may have reduced the risk of future rebellion.

\subsection{Impact on mercenary recruitment activities}

We ran our endline survey at a time of escalating violence in Côte d'Ivoire (CI). The incumbent president, Laurent Gbagbo, lost but disputed a November 2010 election to his rival Alassane Ouattara. Both sides began mobilizing armed forces in December, and there were

\footnotetext{
${ }^{32}$ Net of expenses, including earnings received, cash earned but as yet unpaid, and the estimated value of any in-kind payment.
} 
sporadic outbreaks of violence through February 2011. Serious fighting began in February near the Liberian border. Full-scale war broke out by March. By early April, however, French and UN forces helped to capture and defeat Gbagbo, and hostilities suddenly ceased.

Both sides were accused of recruiting Liberian ex-fighters. Undetermined numbers crossed from Liberia to Côte d'Ivoire starting in December 2010. About 10,000 Liberian mercenaries fought in Côte d'Ivoire during 2002-07 hostilities (ICG, 2011). Our qualitative work and news reports suggest that, by March 2011, no more than 500 Liberian mercenaries had crossed to Côte d'Ivoire. These men were primarily from the capital and border towns, were some of the most experienced ex-fighters, and were offered $\$ 500$ to $\$ 1500$ to join (ICG, 2011). According to one Liberian recruit, "Some of us are not working. Our government [in Liberia] disarmed us, but they have refused to take us into the new army" (Garnaglay, 2011). "We have been in this business for many years," another said. "We know how to fight well and if Gbagbo or Ouattara's men can employ us to fight, that will be good." Several sources - news reports, our informal conversations with peacekeepers, ethnographers, and government, and finally our qualitative interviews with high-risk men during the rising violence generally suggest that most interest in recruitment was opportunistic.

Though they undoubtedly exist, it was difficult to find first- or second-hand accounts of Liberians driven by solidarity or ideology. With the possible exception of the Krahn group (Guère on the Ivorian side), few Liberian ethnic groups had strong ties to one side or the other. The Krahn/Guère held close ties to Gbagbo, however, and their area on the Ivorian side had especially intense violence, took the longest to calm down, and had the most credible rumors of mercenaries.

To the best of our knowledge, none of our sample went to fight in Côte d'Ivoire. This is not surprising given the small numbers that went before the war came to a sudden end. Systematic data on who recruited, and who was recruited, does not exist. Based on our qualitative interviews, some ex-commanders recruited through their networks, and had begun to approach and make offers to ex-fighters to prepare for a longer war. In small communities 
across Liberia, grassroots recruitment activities also proliferated. People, often former midlevel commanders and generals, would hold secretive meetings of former fighters in the village. It's unclear whether these local mobilizers had formal ties to armed groups in Côte d'Ivoire. Rumors circulated widely about the sums promised to men to go, and appropriate terms might be discussed in the meetings. Ex-fighters, if interested, could seek out these meetings, mobilizers, or (in the extreme) make plans to move to one of the border towns where forces were expected to amass. Other men were more likely to be recruited by dint of their profession or location (e.g. in a mining town).

Table 4 lists control means and treatment effects for all 16 self-reported measures in the survey. Some are very indirect proxies for recruitment, and so we display them in a separate sub-index and interpret them cautiously. For instance, $66 \%$ of control men expressed a partisan preference for either Gbagbo or Ouattara, and 68\% said they talked about the war with friends.

Other survey questions, however, reflect more direct demand for or supply of offers, and so are better proxies for interest in recruitment or engagement with recruiters. For instance, $8 \%$ said they had been approached to go fight, $10 \%$ said they were making plans to move to the border are, $4 \%$ said they were invited to go to a secret recruitment meeting, and $3 \%$ reported attending. 3\% also reported being offered money to go. $5 \%$ reported they would go for $\$ 1000$, and $1 \%$ said they had concrete plans to go in the next month. ${ }^{33}$

$45 \%$ had also talked with a commander in the past 3 months. They could talk to a commander for many reasons, of course, but the question is whether a treatment effect reflects a lower likelihood of talking to commanders for reasons of recruitment. Below we show that the program had no statistically significant effect on relationships with ex-commanders. This is one reason we include it in the direct proxies, with these caveats.

12 of the 16 measures (including 9 of the 12 more direct measures) are lower for treated

\footnotetext{
${ }^{33}$ Only $0.5 \%$ were actually found in a Côte d'Ivoire border town at endline, and there is no variation by treatment status. Including this in our index of direct measures has no effect on the results for the overall recruitment index (Appendix D.3).
} 
Table 4: Program impacts on mercenary recruitment proxies

\begin{tabular}{lccc}
\hline & Control & \multicolumn{2}{c}{ TOT estimate } \\
\cline { 3 - 4 } Outcome & Mean & Coeff. & SE \\
& $(1)$ & $(2)$ & $(3)$ \\
\hline All recruitment interest/actions, z-score & 0.09 & -0.204 & {$[0.079]^{* * *}$} \\
Direct recruitment proxies (0-12) & 0.94 & -0.239 & {$[0.118]^{* *}$} \\
Talked to a commander in last 3 months & 0.45 & -0.108 & {$[0.044]^{* *}$} \\
Would go if called to fight for tribe & 0.05 & -0.015 & {$[0.013]$} \\
Has been approached about going to CI & 0.07 & 0.001 & {$[0.021]$} \\
Would go to CI for $\$ 250$ & 0.01 & -0.006 & {$[0.010]$} \\
Would go to CI for $\$ 500$ & 0.03 & -0.009 & {$[0.012]$} \\
Would go to CI for $\$ 1000$ & 0.08 & -0.041 & {$[0.019]^{* *}$} \\
Will move towards CI border area & 0.10 & -0.022 & {$[0.024]$} \\
Invited to secret meeting on going to CI & 0.04 & 0.004 & {$[0.016]$} \\
Attended secret meeting on going to CI & 0.03 & -0.013 & {$[0.011]$} \\
Was promised money to go to CI & 0.03 & 0.001 & {$[0.014]$} \\
Willing to fight if war breaks out in CI & 0.04 & -0.018 & {$[0.015]$} \\
Has plans to go to CI in the next month & 0.01 & -0.012 & {$[0.009]$} \\
Indirect recruitment proxies (0-4) & 1.48 & -0.158 & {$[0.076]^{* *}$} \\
Talks about the CI violence with friends & 0.68 & -0.046 & {$[0.041]$} \\
Has a partisan preference in CI & 0.66 & -0.117 & {$[0.041]^{* * *}$} \\
Knows people who went to CI to fight & 0.10 & -0.021 & {$[0.019]$} \\
Knows people given money to go to CI & 0.04 & 0.026 & {$[0.016]$} \\
\hline
\end{tabular}

Notes: Columns (2)-(3) report the the effect of treatment on the treated (TOT) via twostage least squares. Regressions include block dummies and baseline covariates. Standard errors are clustered at the village level. See Appendix D.1 for ITT results.

*** $\mathrm{p}<0.01,{ }^{* *} \mathrm{p}<0.05, * \mathrm{p}<0.1$

men than controls, often by large proportions. For example, those who would go for $\$ 1000$ falls $51 \%$, attending a secret meeting falls $43 \%$, planning to move to the border area falls $21 \%$, talking with a commander in the last 3 months falls $24 \%$, and having concrete plans to go drops $86 \%$. Of these, only the treatment effects talking to commanders and willingness to go for $\$ 1000$ are individually significant. Jointly, however, these falls are significantengagement in all 12 more direct recruitment activities falls $24 \%$. The other indirect recruitment indicators fall 11\%, and an index of all 16 recruitment measures falls by 0.2 standard deviations with treatment. In general, the results are fairly robust to excluding some of the 
largest and statistically significant proxies (Appendix D.3).

There are only 21 Krahn in our sample, but the deterrence effect of treatment on mercenary interests is larger rather among this ethnic group, suggesting the program was no less effective when there bonds of solidarity at stake. ${ }^{34}$

Some results are more difficult to explain, such as the decrease in an expressed partisan preference with treatment. This could be evidence of the program offer changing political preferences or grievances. The decision to join an armed group is complex and multifaceted, and elements of glory, grievances, or other motives were surely present. Thus we cannot dismiss other, non-material motives.

\subsection{In-kind inputs versus an expected cash transfer}

These treatment effects conceal heterogeneity in who received the in-kind capital inputs. Assuming agricultural skills and capital are complements, the model predicts that people are less likely to increase farming without capital. The effect on illicit activities is ambiguous, however. In practice, mining and mercenary work requires that men leave the village and risk missing the disbursement. This could dissuade men from illicit work even if agricultural returns are low. Missing the disbursement is akin to a punishment in our model.

We estimate the effect of choosing animals in Table 5, which estimates the ITT with an additional indicator for whether the man chose animals. The coefficient on treatment alone reflects the effect of choosing farming (columns 1 and 2), the coefficient on the animals indicator gives the marginal effect of that choice (in columns 3 and 4), and the sum of these two coefficients is the total program impact on those who chose animals (in columns 5 and $6)$.

We see that those who chose animals are less likely to increase their agricultural engagement or hours of work. The decrease is not statistically significant, but the decrease in

\footnotetext{
${ }^{34}$ We present details in Appendix D.4. Similarly strong Liberian ties did not exist for the (largely Muslim) opposition group, and being Muslim in our sample is a poor predictor of support for the Ivorian opposition forces.
} 


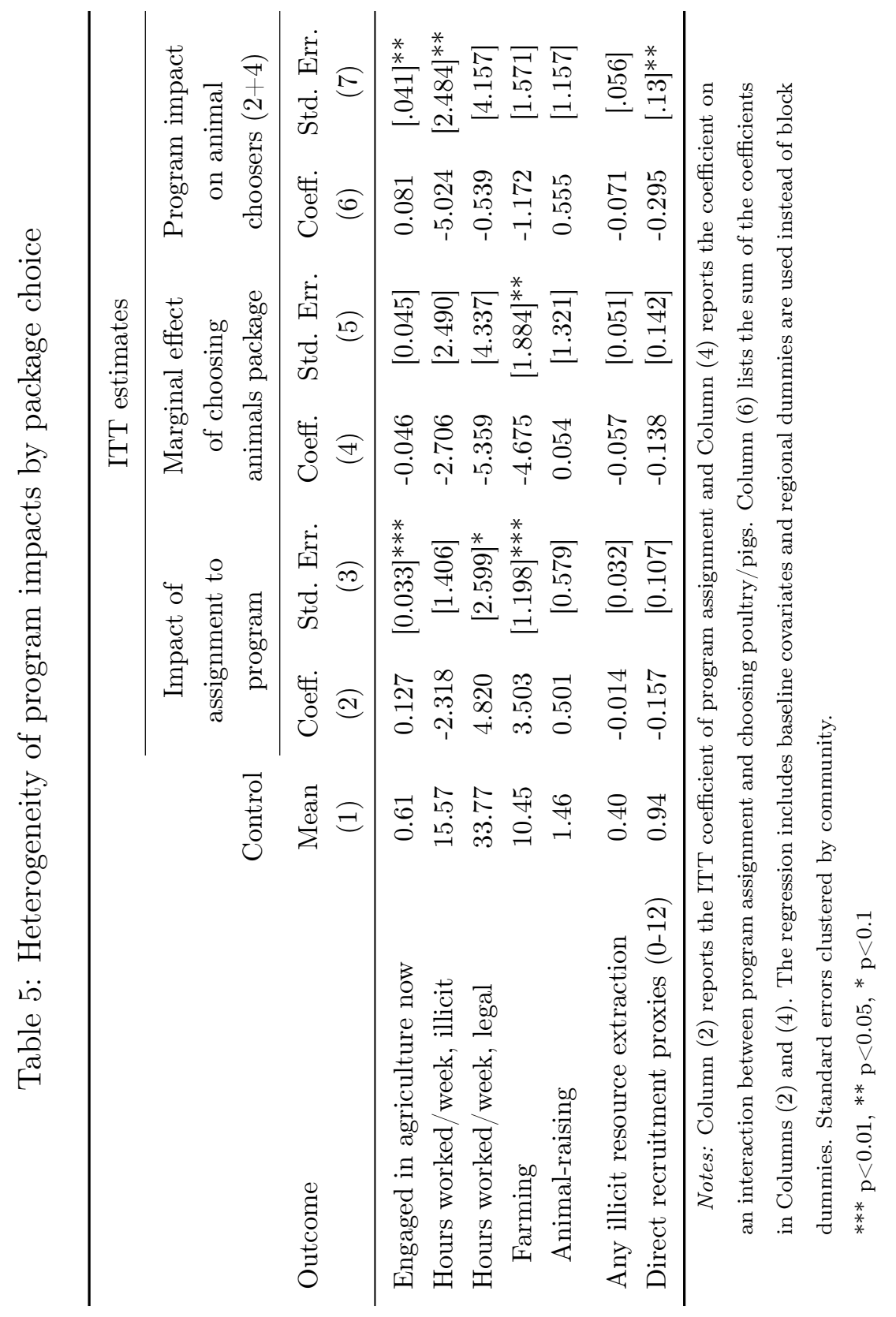


hours farming is. Illicit activities fall in both groups, though they appear to fall most in the animals group (the difference is not statistically significant).

The fall in both illicit resource extraction and mercenary recruitment activities is largest, however, among those who chose to specialize in animals and were told to expect a transfer. This is consistent with men staying in villages to await the transfer. ${ }^{35}$ These estimates are not sensitive to serious violations of the assumption of conditional unconfoundedness (Appendix D.3).

\subsection{Could results be biased by self-reported data?}

One concern with these effects is they use self-reported data. If the treated feel pressure to report good behaviors (experimenter demand) then we overestimate impacts on them. This is a challenge in developing countries where administrative data are nonexistent.

Measurement error is a risk, but there are several reasons to think it is a modest one. First, the patterns we observe are inconsistent with the obvious incentives to misreport. The counseling and life skills components of the program stressed certain forms of behavior change: ending use of war names, lowering interpersonal aggression, and solving disputes peacefully, among other behaviors. Occupational choice, including resource extraction, was not discussed. Thus if treated men have a tendency to report "good" behavior to surveyors, we should expect treatment effects to be largest for the behaviors emphasized by their counselors. Below we will see the opposite is true.

Second, since resource extraction and mercenary actions mainly decrease among animal choosers, the incentives to misreport would have to be correlated with expecting cash specifically, not treatment in general. While feasible, it is puzzling that we do not see this pattern appear in the good behaviors explicitly emphasized by the program. Furthermore, the control group, who were eligible for future training, did not respond to a similar incentive.

\footnotetext{
${ }^{35}$ This presumes AoAV's promises were credible after failing to deliver for a year. Our qualitative interviews suggest that while men were worried about this, most believed AoAV would deliver, largely because they delivered on previous promises of training, the sty/coop materials, and materials to other men in the village who chose vegetables.
} 
Third, we attempted to measure social desirability bias in a similar sample. Logistically it was not possible to validate data for our dispersed, mobile group. Instead, we conducted a survey validation exercise in the capital among high-risk men in the slums of Monrovia, especially men engaged in petty crime. These men were part of a field experiment that tested a similar program of rehabilitation, detailed in Blattman et al. (2015). Briefly, Liberian qualitative researchers shadowed and interviewed 240 men for four days within ten days of a written survey. They used in-depth observation, interviews, open-ended questioning, and efforts at trust-building to elicit more truthful answers about theft, drug use, and gambling from a random subsample of experimental subjects. Comparing these response to survey data, we find little evidence of measurement error. If anything, it seems the control group underreported sensitive behaviors and expenditures, meaning the true treatment effects are larger than estimated.

\subsection{Socio-political impacts}

Finally, we see no evidence the program successfully socialized the men differently, including the aims of the counseling and life skills: peer groups, risky social networks, anti-social behaviors, community engagement and leadership, and attitudes to violence.

Table 6 reports control group means and TOT estimates for several family indices plus a subset of the index components as examples (Appendix D.1 lists all components). We see no evidence the program broke down military chains of command or interaction among ex-combatants, perhaps because the training intensified exposure to ex-combatants and commanders. An index of four measures of ex-combatant relationships increases 0.073 standard deviations (not significant). An index of relationships with former commanders declines 0.154 standard deviations among treated men (also not significant). Treated men do report small decreases in close relations with a commander, or receiving support or jobs from a commander.

We also asked respondents about their closest friends and whether or not they have 
19 different qualities ranging from "positive" (e.g. have a business or job, participate in community meetings) or "negative" ones (e.g. get drunk regularly, use drugs, steal, or have conflicts with the authorities). An index increasing in positive qualities and decreasing in negative ones is 0.027 standard deviations higher among the treated (not significant). Table 4 displays 6 such qualities. None of the negative qualities and only one of the positive qualities (having a business or job) increase with treatment.

Table 6: Program impacts on social relations, networks and peers

\begin{tabular}{lccc}
\hline & Control & \multicolumn{2}{c}{ TOT estimate } \\
\cline { 2 - 4 } Outcome & Mean & Coeff. & SE \\
& $(1)$ & $(2)$ & $(3)$ \\
\hline Ex-combatant relations, 4 measures (z-score) $\dagger$ & 0.07 & 0.073 & {$[0.080]$} \\
Has friends who are ex-combatants & 0.58 & 0.111 & {$[0.046]^{* *}$} \\
Half or more of friends are ex-combatants & 0.50 & -0.018 & {$[0.044]$} \\
Fought in the same unit with these friends & 0.38 & 0.03 & {$[0.036]$} \\
Talks to them about good times during war & 0.13 & -0.065 & {$[0.083]$} \\
Ex-commander relations, 4 measures (z-score) & 0.02 & -0.154 & {$[0.100]$} \\
Has friends who are former commanders & 0.20 & 0.006 & {$[0.041]$} \\
Has close relations with a former commander & 0.30 & -0.055 & {$[0.036]$} \\
Former commanders give support or jobs & 0.08 & -0.017 & {$[0.026]$} \\
Currently reports to a commander & 0.04 & -0.012 & {$[0.015]$} \\
Peer group qualities, 19 measures (z-score, with bad & & & \\
qualities reducing index) $\dagger$ & & & \\
Have a business or a job & 0.05 & 0.027 & {$[0.063]$} \\
Comfort you when you are feeling bad & 0.58 & 0.072 & {$[0.035]^{* *}$} \\
Can be trusted to guard your valuables & 0.90 & 0.042 & {$[0.027]$} \\
Use drugs & 0.87 & 0.003 & {$[0.024]$} \\
Steal other people's property & 0.06 & -0.014 & {$[0.020]$} \\
Often have conflicts with authorities & 0.03 & 0.004 & {$[0.013]$} \\
Quality of social relations & 0.05 & 0.024 & {$[0.017]$} \\
Index of social support received (z-score) $\dagger$ & & & \\
Index of family relations (z-score) $\dagger$ & -0.06 & 0.188 & {$[0.085]^{* *}$} \\
\hline Notes: We cst & -0.00 & 0.133 & {$[0.075]^{*}$} \\
\hline
\end{tabular}

Notes: We estimate the effect of treatment on the treated (TOT) via two-stage least squares. All regressions include block dummies and baseline covariates. Standard errors clustered at the village level. See Appendix D.1 for ITT estimates.

$\dagger$ See Appendix D.1 for all index components

*** $\mathrm{p}<0.01, * * \mathrm{p}<0.05, * \mathrm{p}<0.1$ 
Treated men do, however, report better support from existing networks. Table 6 reports an index of 8 questions about forms of social support received in the past month (such as people who gave them advice, financial support, etc.) and 7 questions about family relationships (such as frequency of interaction or whether there are serious disputes). Social support is 0.19 standard deviations higher among the treated, and the family index is 0.13 standard deviations greater (significant at the $10 \%$ level).

Table 7: Program impacts on anti-social behavior and attitudes to violence and democracy

\begin{tabular}{lcccc}
\hline & Control & \multicolumn{2}{c}{ TOT estimate } \\
\cline { 2 - 4 } Outcome & Mean & Coeff. & SE \\
& $(1)$ & $(2)$ & $(3)$ \\
\hline Antisocial behaviors, 13 measures (z-score) $\dagger$ & -0.06 & 0.036 & {$[0.078]$} \\
$\quad$ Was unable to control your anger (past month) & 0.48 & 0.058 & {$[0.056]$} \\
Threatened people (past month) & 0.10 & 0.002 & {$[0.035]$} \\
Took other people's things (past month) & 0.03 & 0.060 & {$[0.023]^{* * *}$} \\
Had a fight or angry dispute (past 6 months) & 0.70 & 0.000 & {$[0.138]$} \\
Uses a war name (nom de guerre) & 0.32 & -0.009 & {$[0.045]$} \\
Approval for use of violence, 12 measures (z-score) $\dagger$ & -0.05 & -0.064 & {$[0.072]$} \\
Neighbor beats the man who robbed his home & 0.08 & -0.032 & {$[0.018]^{*}$} \\
Take things from home of man refusing to repay you & 0.04 & -0.001 & {$[0.015]$} \\
Community beats a corrupt leader & 0.07 & -0.005 & {$[0.019]$} \\
Community beats policeman bribed to release rapist & 0.22 & -0.042 & {$[0.033]$} \\
Community participation/leadership, 13 measures (z-score) $\dagger$ & -0.01 & 0.112 & {$[0.074]$} \\
Is a community leader & 0.29 & -0.024 & {$[0.034]$} \\
Contributed to care of community water sources & 0.67 & 0.027 & {$[0.043]$} \\
People often come to you for advice & 0.38 & 0.018 & {$[0.039]$} \\
Community members come to you to solve disputes & 0.28 & 0.015 & {$[0.039]$} \\
Attitudes to democracy, 10 measures (z-score) & 7.50 & -0.164 & {$[0.131]$} \\
\hline
\end{tabular}

Notes: We estimate the effect of treatment on the treated (TOT) via two-stage least squares. All regressions include block dummies and baseline covariates. Standard errors clustered at the village level. See Appendix D.1 for ITT estimates.

$\dagger$ See Online appendix D.1 for all index components

$* * * \mathrm{p}<0.01,{ }^{* *} \mathrm{p}<0.05,{ }^{*} \mathrm{p}<0.1$

Table 7 looks at the pro- and anti-social behaviors targeted by the intervention. Again we report family indexes with examples of the components. We see no significant change in 
an index of 13 questions about aggressive and other anti-social behaviors in the past four weeks (such as threatening people, destroying their property, or having physical fights). Also, about a third of the control group use a nom de guerre, a practice actively discouraged by the facilitators as a symbol of personal change. Treatment has no effect on its use.

We also asked about 12 attitudes towards violence as a means of maintaining order or justice (such as mob justice). The index is 0.064 standard deviations lower among the treated (not significant). We asked 13 questions about community participation and leadership (such as attending community meetings, or contributing to public goods). An index of these is 0.112 standard deviations greater among the treated (not significant). Finally, we see no significant

difference in 10 measures of pro-democratic attitudes, such as whether they disapprove of military coups when the President's performance is bad.

\section{Discussion and conclusions}

There have been few opportunities outside the US to test the effects of labor market interventions on illegal and rebellious activity. This intervention shows that increasing agricultural productivity and capital led men to shift away from illicit resource extraction on the intensive but not the extensive margin. The extensive margin responded more to future and ongoing incentives - a conditional cash transfer - rather than a one-time increase in capital and productivity. These patterns resemble what a simple, standard model of occupational choice predicts.

Implications for illicit labor markets and economic rehabilitation First, programs often assume that former fighters, gang members, or other high-risk young men are uninterested in traditional occupations like farming. This belief may come from asking young men "What do you want to be?" rather than "What do you think you will be?" But farming is the main economic opportunity in Liberia, a point both AoAV and the highest-risk men understood. Farming is not especially lucrative but it is respectable and commonplace, and 
indeed necessary for most households for their lifetime. Thus most of them were keen to improve their knowledge.

Second, the response to the promise of a future cash transfer is insightful. It suggests that one-time transfers of skills and capital may have limited deterrent effects on future violence. That is, the most effective peace dividends may pay out repeatedly over time. Capital transfers or cash-for-work programs could accomplish the same if they condition payment on men's location-out of hotspots and not in mercenary work. ${ }^{36}$

Third, our results are consistent with a growing body of evidence that suggests that employment programs should emphasize capital alongside skills. Men who received training and were waiting for their capital were unable to start their farms. This is consistent with our theoretical model: if people are poor and credit-constrained then the returns to skills alone will be low. This is also consistent with studies of business skills and vocational training, which show limited impacts on men and seldom pass a cost-benefit test (e.g. Attanasio et al., 2011; McKenzie and Woodruff, 2012; Cho et al., 2013). A growing number of studies, moreover, show that the poor have high returns to capital. ${ }^{37}$ In the AoAV program, a reasonable hypothesis is that increasing the availability of capital, or even changing the ratio of skills to capital provided, would increase cost-effectiveness. This is unknown, however, and an important question for future study.

Fourth, the elasticity of illegal labor supply suggests the returns to mining and other resource extraction were not much greater than agriculture to begin with. Given free entry into illicit resource extraction, it's perhaps not surprising that returns are competitive with other opportunities. There are interesting parallels to studies of US drug gangs that finds that the lowest positions are quite poorly paid, labor supply is elastic, but on the intensive margin only (Levitt and Venkatesh, 2000). As a result, to persuade men to exit rather than simply decrease illicit activities, a single-sector focus may be insufficient. Programs that

\footnotetext{
${ }^{36}$ Cash-for-work can also have a direct "incapacitation" effect, in the same sense that schooling and training programs are thought to affect crime in large part because they keep high-risk men off the streets (Freeman, 1999).

${ }^{37}$ e.g. Haushofer and Shapiro (2013); Blattman et al. (2014); Banerjee et al. (2015); Blattman et al. (2015).
} 
promote both farm and non-farm business (such as petty trading), perhaps by providing more liquid capital, could reduce risk and hence incentives for illicit work. This is another important area for research.

Economic incentives might not be enough. The model (and common sense) also imply that increasing policing and punishment could lead to criminal exit, especially combined with higher legal wages. Illicit resource extraction was an appealing alternative partly because of low enforcement. But the aftermath of conflict, it may be easier to change labor market opportunities than strengthen police forces, at least in the short term.

Implications for theories of armed recruitment The findings are also largely consistent with the idea that armed recruitment responds to material incentives. First, we see large impacts on returns to legal work (and the opportunity cost of illegal work), but no statistically significant evidence of impacts on the behaviors and attitudes associated connections to commanders, peer quality, non-material forms of violence, community participation, or attitudes to crime and violence. The program only affected antisocial behaviors with material incentives. Third, the decrease in both illicit activity and proxies for interest in recruitment activities is largest among men with future economic incentives not to leave the village.

This is not to say that demand drivers do not matter. Armed social networks, ethnic solidarity, and grievances undoubtedly influenced men's interest in mercenary work. And these drivers may have played an even larger role in a less opportunistic conflict than the Ivorian one. This general variation in motives is important, but our research design only identifies the subset of the variation that is affected by the randomized treatment. Like any source of causal identification, this exogenous variation is not necessarily representative of all the variation in factors affecting the decision to join an armed group. For the reasons we outline above, the evidence points to the program affecting material incentives most of all.

One possibility, however, is that getting trained and becoming a successful farmer raised men's community esteem and lowered men's social marginalization. This reduced the appeal 
of armed groups as a source of respect and upward mobility. We do see that the program increased social support from friends and family. But there is no significant effect on broader community participation. Probably economic success and social integration are intertwined, and a pure economic opportunity cost is too narrow an interpretation of why jobs and income deter crime and armed recruitment. ${ }^{38}$

Meanwhile, the one piece of evidence that is consistent with an effect of the program on grievances is the reduction in expression of a "partisan preference" in the war. This is difficult to square with a pure opportunity cost motive at work. Relatedly, the one group that had the closest solidarity with a fighting group were less likely to express interest in recruitment than their co-ethnics in the control group. But evidence for the opportunity cost mechanism does not crowd out demand drivers, or vice versa. As our formal model illustrated, they are likely to be complementary.

Implications for rehabilitation strategies Failure to re-socialize men in this case does not mean socialization is futile. Indeed, other programs targeting high-risk urban youth, in both the US and Africa, have successfully changed antisocial behaviors. Successful programs have tended to target specific behaviors and "character" skills, often using the techniques of cognitive behavioral therapy, or CBT (Heller et al., 2013; Heckman and Kautz, 2013; Heller et al., 2015). In urban Liberia, one study shows that eight weeks of non-residential CBT focused on skills of self-control and a noncriminal self-image had large and sustained impacts on violence and crime, especially when combined with cash transfers (Blattman et al., 2015).

In the US rehabilitation literature, "best practices" discourage residential programs (since they do not help people learn to change in their normal environments), and has shown that concentrating "at-risk" men with "high-risk" men tends to increase antisocial behavior (Gendreau and Andrews, 1994; Heckman and Kautz, 2013). They also tend to encourage focused, CBT-style curriculums over lectures or talk therapy. It is possible that a nonresidential program, cognitive-behavioral counseling approach, that treated ex-commanders

\footnotetext{
${ }^{38}$ See Utas (2003) for a similar argument during reintegration a decade earlier in Liberia.
} 
and the highest risk men separately, would have had led to greater social integration. This too is an important area for more research.

Overall, this paper adds to a growing body of evidence that economic margins matter for crime and rebellion. As this evidence solidifies, however, it means non-economic approaches to behavior change are arguably a more important area for future study and policy experimentation, given the paucity of evidence and uncertainty about what works.

\section{References}

Akerlof, G. A. and R. E. Kranton (2000). Economics and identity. Quarterly Journal of Economics 115(3), 715-753.

Attanasio, O., A. Kugler, and C. Meghir (2011). Subsidizing Vocational Training for Disadvantaged Youth in Colombia: Evidence from a Randomized Trial. American Economic Journal: Applied Economics 3(3), 188-220.

Banerjee, A. V. and E. Duflo (2011). Poor economics: A radical rethinking of the way to fight global poverty. New York: Public Affairs.

Banerjee, A. V., E. Duflo, N. Goldberg, D. Karlan, R. Osei, W. Parienté, J. Shapiro, B. Thuysbaert, and C. Udry (2015). A Multi-faceted Program Causes Lasting Progress for the Very Poor: Evidence from Six Countries. Science.

Bazzi, S. and C. Blattman (2014). Economic Shocks and Conflict: Evidence from Commodity Prices. American Economic Journal: Macroeconomics 6(4), 1-38.

Becker, G. S. (1968). Crime and Punishment: An Economic Approach. Journal of Political Economy 76, 169-217. 2.

Berman, E., J. H. Felter, J. N. Shapiro, and M. Callen (2011). Do Working Men Rebel? In- 
surgency and Unemployment in Afghanistan, Iraq and the Philippines. Journal of Conflict Resolution 55(4), 496-528.

Blattman, C., J. Annan, E. P. Green, C. Lehmann, and J. Jamison (2015). The returns to microenterprise development among the ultra-poor: A field experiment in post-war Uganda. Working paper.

Blattman, C., N. Fiala, and S. Martinez (2014). Generating skilled employment in developing countries: Experimental evidence from Uganda. Quarterly Journal of Economics 129(2), $697-752$.

Blattman, C., J. Jamison, and M. Sheridan (2015). Reducing crime and violence: Experimental evidence on adult noncognitive investments in Liberia. Working paper.

Blattman, C. and L. Ralston (2015). Generating employment in poor and fragile states: A review of the evidence from labor market and entrepreneurship programs. Working paper.

Bøås, M. and A. Hatløy (2008). 'Getting in, getting out': militia membership and prospects for re-integration in post-war Liberia. The journal of modern African studies 46(01), $33-55$.

Cho, Y., D. Kalomba, A. M. Mobarak, and V. Orozco (2013). Gender differences in the effects of vocational training: Constraints on women and drop-out behavior. Working paper.

Christensen, M. M. and M. Utas (2008). Mercenaries of Democracy: the 'Politricks' of Remobilized Combatants in the 2007 General Elections, Sierra Leone. African Affairs, $1-25$.

Dube, O., O. Garcia-Ponce, and K. Thom (2014). From Maize to Haze: Agricultural Shocks and the Growth of the Mexican Drug Sector. Working paper. 
Dube, O. and J. F. Vargas (2013). Commodity Price Shocks and Civil Conflict: Evidence From Colombia. Review of Economic Studies 80(4), 1384-1421.

Freeman, R. B. (1999). The Economics of Crime. In O. Ashenfelter and D. Card (Eds.), Handbook of Labor Economics, Volume 5, pp. 3529-3572. Elsevier.

Garnaglay, B. (2011, January). Liberian mercenaries hope for work in Ivory Coast. Reuters.

Gendreau, P. and D. A. Andrews (1994). The correctional program assessment inventory. Technical report, University of New Brunswick, Saint John.

Gilligan, M. J., E. N. Mvukiyehe, and C. Samii (2012). Reintegrating Rebels into Civilian Life: Quasi-Experimental Evidence from Burundi. Journal of Conflict Resolution 57(4), $598-626$.

Grogger, J. (1998). Market Wages and Youth Crime. Journal of Labor Economics 16(4), $756-791$.

Gurr, T. R. (1971). Why Men Rebel. Princeton: Princeton University Press.

Haushofer, J. and J. Shapiro (2013). Welfare Effects of Unconditional Cash Transfers: Evidence from a Randomized Controlled Trial in Kenya. Working paper.

Heckman, J. J. and T. Kautz (2013). Fostering and measuring skills: Interventions that improve character and cognition. NBER Working Paper 19656.

Heller, S. B., H. A. Pollack, R. Ander, and J. Ludwig (2013). Preventing Youth Violence and Dropout: A Randomized Field Experiment. Working Paper.

Heller, S. B., A. K. Shah, J. Guryan, J. Ludwig, S. Mullainathan, and H. A. Pollack (2015). Thinking, Fast and Slow? Some Field Experiments to Reduce Crime and Dropout in Chicago. Working paper. 
Humphreys, M. and J. M. Weinstein (2007). Demobilization and Reintegration. Journal of Conflict Resolution 51, 531-567. 4.

ICG (2011). Liberia: How Sustainable is the Recovery? Technical report, International Crisis Group.

Kingma, K. and R. Muggah (2009, May). Critical Issues in DDR: Context, indicators, targeting, and challenges. Technical report, CIDDR Conference, Colombia.

Levely, I. (2011). Disarmament, Demobilization, Reinsertion and Reintegration in Post-War Liberia: A failed approach or simply a failed program? Working paper.

Levitt, S. D. and S. A. Venkatesh (2000). An Economic Analysis of a Drug-Selling Gang's Finances. Quarterly Journal of Economics 115, 755-789. 3.

McKenzie, D. J. and C. Woodruff (2012). What are we learning from business training and entrepreneurship evaluations around the developing world? Working paper.

Merton, R. K. (1938). Social Structure and Anomie. American Sociological Review 3, 672682. 5 .

Miguel, E., S. Satyanath, and E. Sergenti (2004). Economic Shocks and Civil Conflict: An Instrumental Variables Approach. Journal of Political Economy 112, 725-753. 4.

Nussio, E. and B. Oppenheim (2014). Anti-Social Capital in Former Members of Non-State Armed Groups: A Case Study of Colombia. Studies in Conflict \& Terrorism 37, 999-1023.

Popkin, S. L. (1979). The Rational Peasant: The Political Economy of Rural Society in Vietnam. Berkeley: University of California Press.

Republic of Liberia (2008). Liberia Poverty Reduction Strategy. IMF Country Report 08/219, Monrovia, Liberia.

Tajima, Y. (2009). Background Paper on Economic Reintegration. 
Utas, M. (2003). Sweet battlefields: Youth and the Liberian civil war. Uppsala, Sweden: Uppsala University Dissertations in cultural anthropology. 1.

Walter, B. F. (2004). Does Conflict Beget Conflict? Explaining Recurring Civil War. Journal of Peace Research 41,371-88. 3.

Wood, E. J. (2003). Insurgent Collective Action and Civil War in El Salvador. New York: Cambridge University Press.

World Bank (2012). World Development Report 2013: Jobs. Washington. 


\section{Appendix for online publication}

\section{A Program, curriculum, and budget details}

This section details the nature, content, and cost of the program. Table A.1 reports statistics on program attendance and choices.

Table A.1: Program attendance, performance and choices

\begin{tabular}{|c|c|c|c|}
\hline \multirow[b]{2}{*}{ Program choice or outcome } & \multicolumn{3}{|c|}{ Sample } \\
\hline & $\begin{array}{c}\text { Men assigned to } \\
\text { treatment }\end{array}$ & $\begin{array}{l}\text { Men assigned to } \\
\text { treatment who } \\
\text { attended }\end{array}$ & $\begin{array}{c}\text { Men assigned to } \\
\text { treatment who } \\
\text { graduated }\end{array}$ \\
\hline Attended $>1$ day of training & $74 \%$ & & \\
\hline \# training days completed & 83.74 & 113.03 & 117.63 \\
\hline Graduated & $69 \%$ & $94 \%$ & \\
\hline Migrated since baseline & $48 \%$ & $46 \%$ & $46 \%$ \\
\hline Received part 1 of package & $65 \%$ & $88 \%$ & $93 \%$ \\
\hline Received part 2 of package & $34 \%$ & $46 \%$ & $49 \%$ \\
\hline Chose vegetable package & & & $60 \%$ \\
\hline Chose poultry or pigs package & & & $28 \%$ \\
\hline Chose rubber package & & & $7 \%$ \\
\hline Chose other package & & & $5 \%$ \\
\hline \multicolumn{4}{|l|}{$\%$ that received both packages: } \\
\hline Chose vegetable & & & $67 \%$ \\
\hline Chose poultry or pigs & & & $7 \%$ \\
\hline Chose rubber & & & $70 \%$ \\
\hline Chose other & & & $48 \%$ \\
\hline Sold part of packages & & & $5 \%$ \\
\hline Observations & 586 & 433 & 407 \\
\hline
\end{tabular}

\section{A.1 Agricultural training curriculum}

The syllabus for the Bong site (called the Tumutu Agricultural Training Program) has 5 major modules. The learning objectives and outcomes for each module is as follows:

1. Rice PROduCtion (72 hours). After participating in all the module-training activities (both theory and practical sessions) the trainee is expected to gain broader knowledge 
on the growth and development of the rice plant and the use of sustainable agricultural methods in rice production, and link rice production to household/national food security and markets for sustainable livelihoods. At the end of the six month training in rice production, the trainee should be able to:

(a) Understand and be able to produce upland and lowland rice

(b) Gain a broader knowledge of the importance of proper management of natural resources (soil and water) and the environment for sustainable rice farming

(c) Develop swamp beds for rice production

(d) Identify sources/types/quality of rice seed and the advantages of using high quality seed adapted to the local conditions

(e) Lay out, establish, and maintain a nursery

(f) Understand and implement techniques for transplanting/planting of rice seed

(g) Understand the different growth stages in rice development

(h) Maintain a rice field ensuring sustainable management of soil nutrients and optimum conditions for rice growth

(i) Develop capacity to identify diseases and pests and to implement the necessary control and or treatment measures

(j) Understand techniques for sustainable and profitable harvesting, processing, and storage of rice

(k) Understand the importance of markets in rice production systems

2. RubBer Culture (72 hours). After participating in all the module-training activities (both theory and practical sessions) the trainee is expected to develop broader knowledge on sustainable rubber production through the use of sustainable agricultural methods and develop capacity to practice rubber farming and/or gain skills for 
employment in the rubber industry for sustainable livelihoods. At the end of the six month training in rubber production, the trainee should be able to:

(a) Understand the importance of rubber in Liberia

(b) Techniques for bark maintenance, tapping, and latex collection

(c) Develop capacity to establish and maintain a nursery

(d) Prepare pre-germination beds

(e) Establish bud wood garden

(f) Develop techniques for budding

(g) Conduct tasking, paneling, furnishing and opening

(h) Develop sustainable tapping systems and methods

(i) Prepare and apply solution (Latex, Coagulum and Cup - Lump)

(j) Develop capacity for quality control in rubber production

(k) Understand disease and pest management in rubber production

(l) Maintain production equipment

(m) Develop skills for plantation management, product storage, marketing and post harvest management

3. Vegetable Production (72 hours). After participating in all the vegetable production module-training activities (both theory and practical sessions) the trainee is expected to develop broader knowledge on small-scale vegetable production through the use of sustainable agricultural methods and locally available resources and develop capacity to practice vegetable farming for household consumption and produce a surplus for market-ing thereby securing livelihoods income. At the end of the six month training in rubber production, the trainee should be able to: 
(a) Understand the importance of vegetable production for household and national food security

(b) Understand and classify types of vegetables

(c) Develop knowledge on the proper usage and maintenance of tools in vegetable production

(d) Understand the importance of and operate records in vegetable production

(e) Understand the factors considered for vegetable production site selection and prepare selected land sites for production

(f) Establish and maintain a vegetable nursery

(g) Implement different vegetable production systems

(h) Develop capacity for sustainable disease and pest management

(i) Understand the benefits of organic manuring for sustainable natural resource management and food quality

(j) Understand compost making and manure selection and application

(k) Understand and develop capacity to harvest different types of vegetables including quality control and storage

(l) Understand the importance of markets in vegetable production.

4. Tree CROps/OIL PALm (106 hours). After participating in all the tree crops production module-training activities (both theory and practical sessions) the trainee is expected to gain broader knowledge on how to grow oil palms through the use of sustainable agricultural methods and develop capacity to practice oil palm farming as a cash crop and be in a position to generate an income for long-term sustainable livelihoods. At the end of the six month training in oil palm farming, the trainee will be expected to:

(a) Understand the importance of oil palm as a cash crop 
(b) Understand the required soil and climatic conditions

(c) Be able to select varieties best suited for their communities

(d) Lay out paths and nursery beds and put up shelters in the nursery

(e) Understand factors determining plantation site selection

(f) Carry out pegging of the plantation pattern, planting out the oil palm seedlings and fencing around the seedlings

(g) Learn how to maintain an oil palm plantation (e.g. cultivation, trimming the plants, soil nutrient and water management)

(h) Implement sustainable pest and disease management practices

(i) Understand methods of and be able to implement oil palm harvesting, processing and storage

(j) Understand the importance of markets in oil palm production and develop capacity to access and derive benefits from the market.

5. Animal husbandry ( 78 hours for poultry, 89 for pigs, and 55 for rabbits). The training module is designed for beginners to provide fundamental theory of tools, materials and work practices in animal production (poultry, rabbitory and piggery). After participating in all the animal husbandry production module-training activities (both theory and practical sessions) the trainee is expected to gain broader knowledge on how to keep poultry, rabbits and pigs for household food security and to be in a position to generate an income through this activity for sustainable livelihoods. At the end of the training in animal husbandry, the trainee will be expected to:

(a) Develop basic skills for poultry, rabbitory and piggery production

(b) Be able to construct required housing for poultry, rabbits and pigs through the sustainable use of locally available resources 
(c) Understand the breeding and reproductive systems and requirements of poultry, rabbits and pigs and the methods used to enhance quality of breeds

(d) Develop capacity to implement disease and parasite prevention and treatment and control in poultry, pig and rabbit production

(e) Develop capacity for animal slaughter (poultry, rabbits and pigs) with an emphasis on animal welfare, quality control and hygienic standards including preservation methods

(f) Understand the importance of markets in poultry, pig and rabbit production and strengthen skills to compete profitably

\section{A.2 Life skills curriculum}

For the life skills class and on-site counseling, AoAV contracted members of the Network for Empowerment and Progressive Initiative (NEPI), a local non-profit organization. NEPI had developed and implemented previous programs in Liberia with war-affected youth and AoAV used and adapted their curriculum for this program. The stated goal was to transform the lives of participants so they may become more productive members of society. More broadly, the class and counseling is designed to help the war affected improve their coping mechanisms to trauma; and foster relationships between and amongst former fighters, conflicting parties, varying socioeconomic groups, and tribal factions; and promote peace and reconciliation principles as tools to effectively build, strengthen, and promote positive social change within communities. NEPI trainers and facilitators are largely former combatants themselves who perform social work and other social services for war-affected youth. These counsellors serve as the participants' strongest positive role models. The curriculum itself has 17 major modules:

1. Effective communication (Definition; Types; Barriers; Ways of Improving; Listening Skills) 
2. Perception and role reversal (Definition; Case Study; The Way Forward)

3. Understanding conflict (Definition; Types; Causes; Effects; Tools for Conflict Management; Tools for Conflict Resolution)

4. Conflict analysis and transformation (Definition; Strategies; History; People; Tools for Conflict Analysis \& Transformation)

5. Violence and its cycle (Definition; Types; Causes; Effects; Breaking the Cycle of Violence)

6. Understanding trauma and substance abuse (Effects of Trauma; Definition; Types, Causes and Effects; The Way Forward)

7. Post-traumatic stress disorder (Definition; Causes; Symptoms and Signs; Developing Coping Mechanism)

8. Career counseling (Definition; Types; Importance of Career; Career Selection; Two aspects of Career; Principles for Effective Career)

9. Self image and recovery (Definition; Types; The Building Process)

10. Early warning and early response (Definition, Group Discussion. Mechanism for Prevention \& Transformation, The Way Forward

11. Community outlook (Definition; Structure; Norms; Realization \& Transformation; Reintegration)

12. Community initiatives and development (Definition; Types; Ownership and Sustainability)

13. Peace building - Levels and approaches (Definition; Role of a Peace Builder; Peace Keeping; Peace Making; Peace Building) 
14. Challenges of reconciliation (What is Reconciliation?; Steps to Reconciliation; Religious \& Traditional Perspectives of Reconciliation; Dilemmas of Reconciliation; Sustaining Reconciliation Work)

15. Leadership styles and skills (What is leadership?; Why is it important?; Can Leadership be Learned?; Best Leader/Role model; Characteristic of Admired Leadership; Your Leadership Strengths; Seven Critical Leadership Skills; Approaches to Decision Making)

16. General review

17. Re-entry strategies (Identifying communities for the purpose of possible re-insertion of trained participants; Confidence building meetings with community leadership; Linking participants to host communities)

\section{A.3 Example of program budget}

Table A.2 reports the budget AoAV submitted (via the UNDP) to the UN Peacebuilding Fund in 2008 to funding two training courses of 400 students each at the Bong training site. The first cycle was the focus of the evaluation. Figures reflect the high cost of any operations and supplies in Liberia, as with many post-conflict regions. 
Table A.2: Sample budget from Bong course site

\begin{tabular}{lcc}
\hline & \multicolumn{2}{c}{ Cost in USD (2 courses, 800} \\
& \multicolumn{2}{c}{ beneficiaries) } \\
\cline { 2 - 3 } Expense category & Total & \\
\hline Personnel & 300,000 & 375 \\
National and international staff & 10,000 & 13 \\
Subcontractors (counselors/life skills trainers) & & \\
Course costs & 100,000 & 125 \\
Course equipment & 140,000 & 175 \\
Food and medical supplies & 50,000 & 63 \\
Other course costs & 100,000 & 125 \\
Reintegration packages & & 175 \\
Operations expenses & 140,000 & 63 \\
Transport, fuel and maintenance & 50,000 & 138 \\
Travel & 110,000 & 26 \\
Office, utilities and communications & 21,000 & 1,276 \\
Headquarters support & $1,021,000$ & 92 \\
\hline Sub-total & 73,500 & 63 \\
UNDP fee & 50,000 & 1,431 \\
Contribution to randomized evaluation & $1,144,500$ & \\
\hline Total & & \\
\hline
\end{tabular}

\section{B Further details on empirical strategy}

\section{B.1 Baseline covariates and balance}

Table B.1 displays summary statistics for the 83 baseline covariates used in the treatment effects regressions along with baseline tests of balance. The first column reports the mean among all men, and the second column for women. Women are different in several respects: they are younger and less likely to be married or partnered - an uncommon situation for adult women in Liberia. A quarter admits to sex work, but qualitatively our sense is that this is much higher. Very few are ex-combatants and aggression is low.

The third and fourth columns display the mean difference between control and treatment men, based on an OLS regression of each baseline covariate on an indicator for treatment assignment, controlling for block fixed effects only (with standard errors clustered at the 
village level). 6 of the 83 covariates $(7 \%)$ have a p-value less than 0.10 , which is no more than would be expected at random.

Two of the 83 baseline covariates do show significant imbalance: savings and months spent in a faction. A joint test of significance of all 83 baseline covariates has a p-value of .41 excluding these two covariates, but is $<.01$ including them. Other variables related to wealth, debts, armed group activity, and violence have little association with treatment.

Table B.1: Baseline descriptive statistics and test of randomization balance

\begin{tabular}{|c|c|c|c|c|}
\hline \multirow[b]{2}{*}{ Baseline covariate } & \multicolumn{2}{|c|}{ Means } & \multicolumn{2}{|c|}{ Balance test (men only) } \\
\hline & $\begin{array}{l}\text { All men } \\
(\mathrm{n}=1123)\end{array}$ & $\begin{array}{l}\text { All women } \\
\qquad(\mathrm{n}=151)\end{array}$ & $\begin{array}{c}\text { Difference } \\
\text { (Control - } \\
\text { Treatment) }\end{array}$ & p-value \\
\hline Missing baseline data & 0.01 & 0.07 & -0.00 & 0.54 \\
\hline Age & 30.28 & 26.17 & -0.62 & 0.26 \\
\hline Muslim & 0.15 & 0.13 & -0.00 & 0.97 \\
\hline Gola tribe & 0.05 & 0.07 & -0.01 & 0.38 \\
\hline Kpelle tribe & 0.34 & 0.38 & 0.01 & 0.80 \\
\hline Kru tribe & 0.09 & 0.02 & 0.00 & 0.75 \\
\hline Mano tribe & 0.11 & 0.18 & 0.01 & 0.60 \\
\hline Sapo tribe & 0.11 & 0.01 & -0.01 & 0.54 \\
\hline Lives with spouse/partner & 0.71 & 0.51 & -0.03 & 0.22 \\
\hline Number of children & 2.34 & 1.68 & -0.21 & 0.15 \\
\hline Currently pregnant & & 0.04 & & \\
\hline Disabled & 0.06 & 0.05 & 0.00 & 0.89 \\
\hline Injured & 0.23 & 0.20 & -0.02 & 0.39 \\
\hline Seriously ill & 0.14 & 0.21 & 0.01 & 0.52 \\
\hline \# days drank alcohol in the past week & 1.00 & 0.37 & -0.09 & 0.38 \\
\hline Index of risk seeking $(0-3)$ & 0.33 & 0.33 & 0.04 & 0.37 \\
\hline Index of patience $(0-4)$ & 2.96 & 3.17 & 0.01 & 0.83 \\
\hline Said would attend program if selected & 0.99 & 0.99 & 0.00 & 0.62 \\
\hline Index of wealth (z-score) & 0.01 & -0.38 & -0.01 & 0.91 \\
\hline Monthly cash earnings (USD) & 47.42 & 29.33 & -4.19 & 0.33 \\
\hline Stock of savings (USD) & 45.79 & 17.70 & -13.07 & 0.02 \\
\hline Saves monthly & 0.25 & 0.16 & -0.01 & 0.75 \\
\hline Debt stock (USD) & 7.45 & 2.83 & -0.57 & 0.59 \\
\hline \multicolumn{5}{|l|}{ Main income source: } \\
\hline Farming and animal-raising & 0.32 & 0.24 & 0.04 & 0.21 \\
\hline Non-agricultural labor or business & 0.29 & 0.58 & -0.03 & 0.36 \\
\hline Sale of hunted meat & 0.04 & 0.02 & 0.01 & 0.46 \\
\hline Potentially illicit activities & 0.33 & 0.03 & 0.00 & 0.94 \\
\hline Firewood/charcoal sales & 0.02 & 0.01 & 0.01 & 0.24 \\
\hline Mining & 0.11 & 0.01 & -0.01 & 0.53 \\
\hline
\end{tabular}




\begin{tabular}{|c|c|c|c|c|}
\hline \multirow[b]{2}{*}{ Baseline covariate } & \multicolumn{2}{|c|}{ Means } & \multicolumn{2}{|c|}{ Balance test (men only) } \\
\hline & $\begin{array}{l}\text { All men } \\
(\mathrm{n}=1123)\end{array}$ & $\begin{array}{l}\text { All women } \\
\qquad(\mathrm{n}=151)\end{array}$ & $\begin{array}{c}\text { Difference } \\
\text { (Control - } \\
\text { Treatment) }\end{array}$ & p-value \\
\hline Rubber & 0.12 & 0.00 & -0.00 & 0.89 \\
\hline Other & 0.08 & 0.14 & -0.01 & 0.76 \\
\hline Days of employment in past week & 5.97 & 4.64 & -0.11 & 0.30 \\
\hline Farming and animal-raising & 2.75 & 1.63 & -0.11 & 0.50 \\
\hline Skilled work & 1.12 & 0.40 & 0.00 & 1.00 \\
\hline Petty business & 1.03 & 1.87 & -0.07 & 0.51 \\
\hline Casual work & 2.16 & 0.83 & -0.16 & 0.28 \\
\hline Rubber tapping & 0.48 & 0.00 & -0.03 & 0.72 \\
\hline Mining & 0.63 & 0.03 & -0.06 & 0.56 \\
\hline Logging & 0.32 & 0.03 & -0.01 & 0.90 \\
\hline Hunting & 0.59 & 0.19 & -0.09 & 0.25 \\
\hline Other & 1.26 & 0.49 & 0.01 & 0.95 \\
\hline Any illicit activities in past week & 0.32 & 0.03 & 0.01 & 0.70 \\
\hline Engaged in paid sex in past year & & 0.25 & & \\
\hline Very interested in farming in the future & 0.87 & 0.81 & -0.01 & 0.56 \\
\hline Prefers ag. training to other skills & 0.28 & 0.25 & -0.01 & 0.68 \\
\hline Can access 10 acres farmland & 0.90 & 0.91 & 0.03 & 0.21 \\
\hline Months of agricultural training & 0.56 & 0.11 & -0.00 & 0.99 \\
\hline \# Years has raised animals & 2.91 & 1.81 & -0.26 & 0.36 \\
\hline \# Years has farmed & 4.76 & 1.79 & -0.13 & 0.75 \\
\hline Times has sold crops & 6.50 & 3.27 & -0.32 & 0.71 \\
\hline Largest land ever farmed (acres) & 20.50 & 16.85 & -0.75 & 0.44 \\
\hline Educational attainment & 5.88 & 3.77 & 0.21 & 0.36 \\
\hline Has very basic literacy & 0.44 & 0.34 & -0.02 & 0.49 \\
\hline Literate & 0.27 & 0.12 & 0.03 & 0.31 \\
\hline Math questions correct (0-5) & 2.33 & 1.50 & 0.19 & 0.04 \\
\hline \multicolumn{5}{|l|}{ Total months of training (including } \\
\hline agricultural training) & 3.02 & 1.74 & 0.01 & 0.99 \\
\hline Distress symptoms (0-3) & 1.16 & 1.36 & 0.02 & 0.54 \\
\hline Post-traumatic stress symptoms (0-3) & 0.93 & 1.13 & 0.05 & 0.11 \\
\hline Index of family relations $(0-18)$ & 13.59 & 11.93 & 0.27 & 0.17 \\
\hline Index of aggressive behaviors $(0-12)$ & 1.29 & 1.71 & 0.12 & 0.25 \\
\hline Dispute with authorities in past year & 0.05 & 0.03 & -0.01 & 0.34 \\
\hline Dispute with neighbor in past year & 0.14 & 0.26 & -0.01 & 0.67 \\
\hline Reports a physical fight in the past year & 0.09 & 0.09 & 0.00 & 0.90 \\
\hline Fought with weapons in the past year & 0.02 & 0.01 & 0.00 & 0.64 \\
\hline Ex-combatant & 0.74 & 0.13 & -0.01 & 0.83 \\
\hline Was on front lines of battle & 0.17 & 0.05 & -0.00 & 0.90 \\
\hline Months in a faction & 27.4 & 6.95 & 5.73 & 0.00 \\
\hline Violent acts committed $(0-3)$ & 0.54 & 0.26 & 0.06 & 0.34 \\
\hline Violent acts experienced (0-9) & 4.82 & 3.64 & -0.01 & 0.94 \\
\hline Violent acts experienced by family $(0-9)$ & 4.64 & 4.68 & 0.02 & 0.82 \\
\hline Feels life better now than during war & 0.98 & 0.99 & 0.02 & 0.05 \\
\hline Regrets wartime actions & 0.56 & 0.36 & 0.08 & 0.01 \\
\hline Problems reintegrating with family & 0.44 & 0.22 & -0.13 & 0.06 \\
\hline
\end{tabular}




\begin{tabular}{lccccc}
\hline & \multicolumn{2}{c}{ Means } & & \multicolumn{2}{c}{ Balance test (men only) } \\
\cline { 2 - 3 } \cline { 5 - 6 } & All men & All women & & $\begin{array}{c}\text { Difference } \\
\text { (Control - }\end{array}$ \\
Baseline covariate & $(\mathrm{n}=1123)$ & $(\mathrm{n}=151)$ & & Treatment) & p-value \\
\hline Problems reintegrating with neighbors & 0.36 & 0.15 & & -0.05 & 0.38 \\
Faction caused trouble for own family & 0.76 & 0.80 & & 0.00 & 0.98 \\
Faction caused trouble for hometown & 0.95 & 1.06 & & -0.02 & 0.79 \\
Faction caused trouble for current town & 0.82 & 0.74 & & -0.08 & 0.26 \\
Commander(s) gives support/jobs & 0.05 & 0.02 & & -0.02 & 0.17 \\
Has close relations with a commander & 0.13 & 0.03 & & -0.01 & 0.62 \\
Reports to a commander & 0.02 & 0.01 & & -0.02 & 0.14 \\
Index of ex-combatant relations (0-10) & 5.48 & 3.11 & & 0.03 & 0.84 \\
Believes war will come again in Liberia & 0.01 & 0.01 & & 0.00 & 0.87 \\
Would become fighter again & 0.02 & 0.01 & & 0.00 & 0.85 \\
Would consider fighting in war elsewhere & 0.01 & 0.01 & & -0.00 & 0.71 \\
\hline
\end{tabular}

Notes: The third and fourth columns report the mean difference between the treatment and control groups, calculated using an OLS regression of baseline characteristics on an indicator for random program assignment plus block (village) fixed effects. USD variables are censored at the 99th percentile. Missing baseline data imputed at the median.

Estimating potential bias from imbalance. One way to assess potential bias from this imbalance is to use all available baseline covariates to predict the main outcomes. "Treatment effects" on these predicted outcomes can approximate the amount of bias we might expect from randomization imbalance. We report these results in Table B.3 for six major outcome families. 
Table B.3: "Treatment effects" on predicted outcomes using baseline covariates

\begin{tabular}{lcc}
\hline Outcome & Full sample & Non-attritors \\
\hline Interest in agriculture index (z-score) & -0.013 & -0.016 \\
Income index (z-score) & {$[.014]$} & {$[.014]$} \\
Hours in potentially illicit activities & -0.018 & -0.020 \\
& {$[.020]$} & {$[.021]$} \\
Average weekly hours in legal activities & 0.132 & 0.136 \\
& {$[.310]$} & {$[.335]$} \\
Relationships with commanders (z-score) & -0.277 & -0.221 \\
& {$[.464]$} & {$[.480]$} \\
Mobilization risk (z-score) & -0.027 & -0.023 \\
& {$[.013]^{* *}$} & {$[.014]$} \\
& -0.005 & -.008 \\
\end{tabular}

\footnotetext{
Notes: Each outcome is regressed on the baseline variables in Table 1 as well as randomization block dummies. Then the fitted value is regressed on assignment to treatment and strata dummies.
}

In general the treatment-control difference is small (e.g. <.02 standard deviations in agricultural interest or income). The sign is also such that the predicted bias leads us to underreport treatment effects. The exception is relationships with commanders, where the predicted bias is negative and statistically significant (probably because of the length of time in a faction variable). As we will see, we see only a weak negative treatment effect on relations with commanders, and already treated this decline with caution, concluding there is little evidence of an effect of treatment on this variable. These predicted bias results only bolster this conclusion.

\section{B.2 Assessing potential bias from endline survey timing}

Roughly two-thirds of the sample was found in the first 10 weeks. The remaining third took three months to track. To reduce bias from the timing of their survey, we first tracked a random half of the unfound, adding the second half after two months.

In principle, this long survey period could introduce bias if late respondents are systematically different and have seasonal or other time-varying outcome responses. For two reasons 
this does not appear to be the case in our sample.

First, there is little difference between those found in the first 10 weeks and those who had migrated and hence took longer to survey and track, implying that timing of the survey is not too systematically selective. A test of balance between those found before and after 10 weeks (not shown, but available on request) shows that those found after 10 weeks were a year younger, were 15 percentage points less likely to be married, and were 2 percentage points less like to be an ex-combatant, but there is no statistically significant difference in baseline wealth, education, health, occupation, income, aggression, or war experiences.

Second, if we compare treatment effects between men found before and after the 10 weeks, or between the two random groups of unfound men, we see generally the same sign and magnitude of treatment effects. Results are not displayed but are available on request.

\section{B.3 Attrition}

Table B.4 presents results from an ordinary least squares (OLS) regression of attrition (being unfound) on treatment assignment, covariates, and block fixed effects.

Note that the program appears to have had only a small effect on migration at the time of the endline. $45 \%$ of both the treatment and control group changed villages since baseline, and $37 \%$ moved within the six months before the survey. The control group was slightly

less likely to change their county than treated men: $14 \%$ of controls changed their county and this is 5.7 percentage points higher among treated men, perhaps because they chose to relocate to more central agricultural markets. $74 \%$ of control men also express an interest in staying in their current community and this settledness is 7.8 percentage points (11\%) higher among treated men.

\section{B.4 Compliance}

Table B.4 analyzes the correlates of compliance (attending at least one day). Also, among those who attend at least one day, it analyzes the correlates of who quits or is dismissed. 


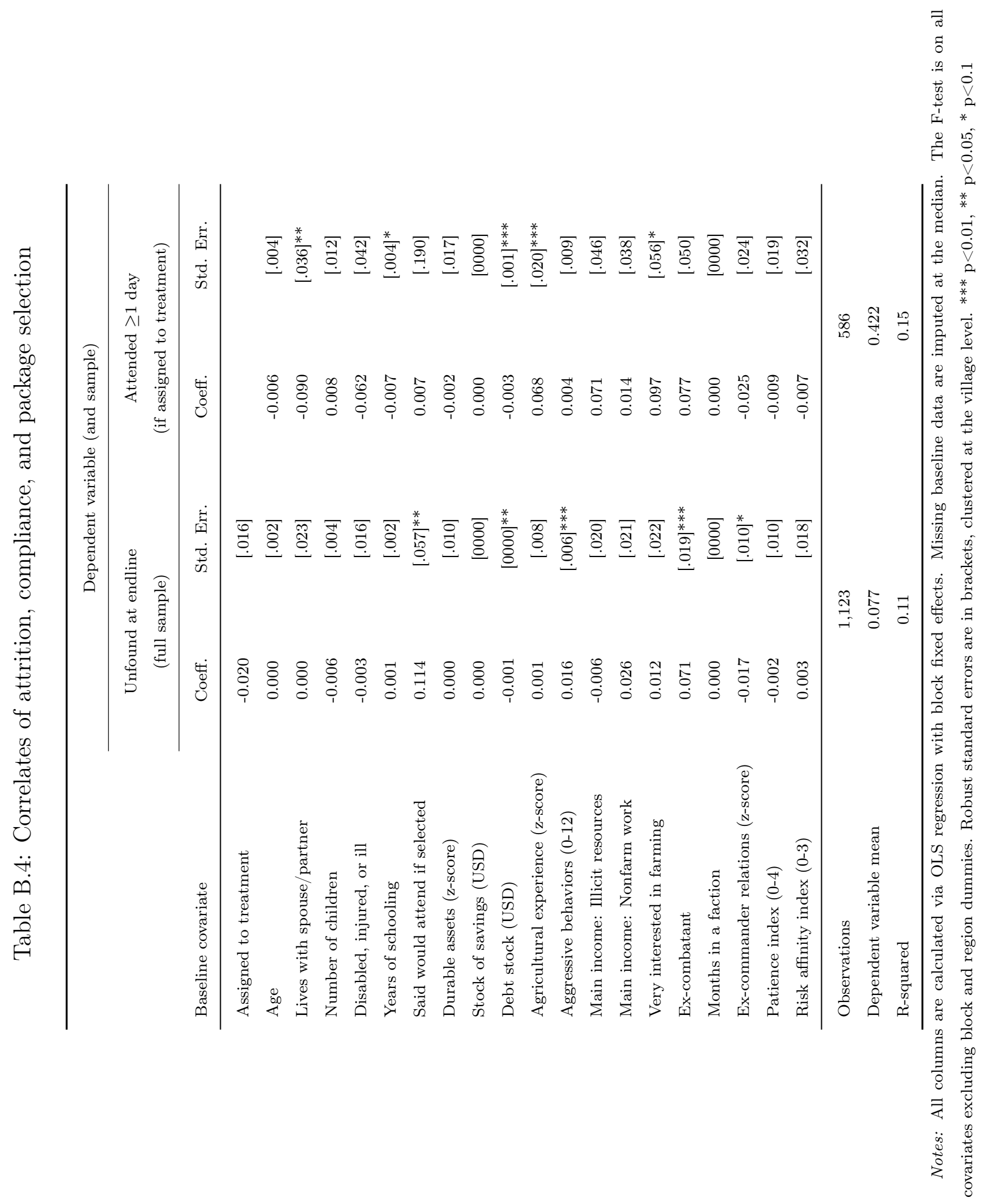




\section{B.5 Accounting for potential spillover effects}

Hotspot communities were limited, and we could not randomize at the community level. It is possible there are unobserved spillover effects from the treatment group to controls.

For instance, the departure of a small number of high risk men from each community could reduce the local labor supply and increase wages for illicit work. It could also break down armed social networks and the power basis of local strongmen, or increase state and UN presence in the community, thus reducing the returns to illicit work. When the trainees return, agricultural knowledge could be passed to the control group, increasing their productivity. Or successful socialization could influence disutility from illicit labor through peer effects.

Accurate population figures do not exist, but we estimate treated men typically represent only 1 to $5 \%$ of the adult workforce in these villages. Also, roughly half of both the treatment and control group changed communities between baseline and endline. Moreover, while transport costs are high in Liberia, there is considerable migration by this population for work, especially in mining and local labor supply is highly elastic (implying that we should not be affected by the departure of a few men). As a result, we expect within-community spillovers to the control group to be minor. Finally, agricultural hours increase just $20 \%$ for

a handful of men per community, and so general equilibrium effects of output on prices seem extremely unlikely.

Moreover, even if present, the spillovers discussed above should not lead us to overstate treatment effects. To the extent that the control group become more productive in agriculture, or are influenced by positive peer effects, our estimated treatment effects towards zero will understate the true program impacts on occupational choice. Any impact on illicit wages will affect the incentives for both treatment and control group members (although control group members would be more affected by an increase in $w$ than someone who received inputs and training).

In principle, individuals who are not assigned to treatment may feel discouraged and 
thus reduce the hours they devote to agriculture, but we see no such trend. Alternatively, returning farmers could have a negative impact on the control group by crowding them out of agriculture or if increased output lowered local prices, but qualitatively our assessment is that production was too small to affect local prices. We do not, however, have the data or identification to test this formally.

\section{A model of illegal occupational choice}

\section{C.1 Setup}

The utility function $U\left(c, l, \sigma L^{m}\right)$ has the standard assumptions that $U_{c}^{\prime} \geq 0, U_{l}^{\prime} \geq 0, U_{\sigma L^{m}}^{\prime} \leq$ 0 and $U_{c c}^{\prime \prime}<0, U_{l l}^{\prime \prime}<0, \partial^{2} U / \partial L_{m}^{2} \leq 0 .{ }^{39}$ The production function $F\left(\theta, L_{t}^{a}, X_{t-1}\right)$ also follows standard assumptions that $F_{\theta}^{\prime} \geq 0, F_{L}^{\prime} \geq 0, F_{X}^{\prime} \geq 0, F_{\theta \theta}^{\prime \prime}<0, F_{L L}^{\prime \prime}<0, F_{X X}^{\prime \prime}<0$, and $F_{\theta L}^{\prime \prime} \geq 0, F_{\theta X}^{\prime \prime} \geq 0, F_{L X}^{\prime \prime} \geq 0 .^{40}$

We begin by ignoring uncertainty and risk aversion. Then we introduce uncertainty in the form of prices, wages, and productivities following independent stochastic processes. Uncertainty in prices can reflect variation in general supply and market conditions, uncertainty in wages can reflect the fact that labor returns are typically conditional on output (e.g. a minimum wage plus a payment proportional to gold or diamonds discovered or battles won), and uncertainty in productivity is a simple way of capturing uncertainty in output due to weather and other unexpected shocks. We keep the assumption that input investment decisions are made one period ahead of production, however we add a new assumption that decision on hours in both sectors $L_{t}^{a}$ and $L_{t}^{m}$ are made at time $t-1$, one period before all

\footnotetext{
${ }^{39}$ Examples of utility functions that satisfy these assumptions are $U\left(c, l, \sigma L^{m}\right)=u(c, l)-\sigma L^{m}$ and $U\left(c, l, \sigma L^{m}\right)=u(c, l)-\sigma\left(L^{m}\right)^{2}$.

${ }^{40}$ For ease of analysis, we also assume that marginal product of labor in agriculture is zero when there is no input; but as long as there is some level of input, marginal product of labor for the first unit of labor will be infinity: $F_{L}^{\prime}\left(\theta, L^{a}, 0\right) \equiv 0$, but $\lim _{L^{a}} F_{L}^{\prime}\left(\theta, L^{a}, X\right)=+\infty$ as long as $X>0$. This assumption guarantees that as long as there is positive investment in inputs, hours in agricultural labor will be positive. We also assume that returns to inputs is non-negative but bounded above $0 \leq F_{X}^{\prime}\left(\theta, L^{a}, X\right) \leq \theta M$ (which is likely the case in agriculture production).
} 
prices and productivity levels are realized.

\section{C.2 Benchmark case: Perfect financial markets and no uncertainty}

We begin with the case where there are no financial market imperfections. The person's problem is

$$
\begin{gathered}
\max _{c_{t}>0,0 \leq l_{t} \leq \bar{L}, X_{t}, L_{t}^{m}, L_{t}^{a}} \sum_{t=0}^{\infty} \delta^{t}\left[U\left(c_{t}, l_{t}, \sigma L_{t}^{m}\right)\right] \\
\text { s.t. } c_{t}+a_{t+1}+q_{t} X_{t}=y_{t}+(1+r) a_{t} \text { for each } t \\
a_{0} \quad \text { given }
\end{gathered}
$$

where $y_{t} \equiv p_{t} F\left(\theta, L_{t}^{a}, X_{t-1}\right)+w_{t} L_{t}^{m}-\rho f L_{t-1}^{m}$ and $L_{t}^{a}+L_{t}^{m}+l_{t} \equiv \bar{L}$.

The first order conditions are as follows:

$$
\begin{aligned}
\frac{U_{l}^{\prime}(t)}{U_{c}^{\prime}(t)} & =p_{t} F_{L^{a}}^{\prime}(t) \quad \text { if } L_{t}^{a}>0 \\
\frac{U_{l}^{\prime}(t)}{U_{c}^{\prime}(t)}-\sigma \frac{U_{\sigma L^{m}}^{\prime}(t)}{U_{c}^{\prime}(t)} & =w_{t}-\frac{\rho f}{1+r} \quad \text { if } L_{t}^{m}>0 \\
\frac{U_{c}^{\prime}(t)}{U_{c}^{\prime}(t+1)} & =\delta \frac{p_{t+1}}{q_{t}} F_{X}^{\prime}(t+1) \quad \text { if } X_{t}>0 \\
\frac{U_{c}^{\prime}(t)}{U_{c}^{\prime}(t+1)} & =\delta(1+r) \\
c_{t}+a_{t+1}+q_{t} X_{t} & =p_{t} F\left(\theta, L_{t}^{a}, X_{t-1}\right)+w_{t} L_{t}^{m}-\rho f L_{t-1}^{m}+(1+r) a_{t}
\end{aligned}
$$

where for ease of notation we use $U(t)$ to denote $U\left(c_{t}, l_{t}, \sigma L_{t}^{m}\right)$ and $F(t)$ to denote $F\left(\theta, L_{t}^{a}, X_{t-1}\right)$.

\section{C.2.1 Occupational choice}

To find the conditions for engaging in each sector, first consider the case where illicit activity is not feasible. In this case the decision to engage in agricultural production depends on his productivity $\theta$, the output-input price ratio $p_{t+1} / q_{t}$, his wealth level and the returns on other financial assets $r$. We use $c^{a a}, L^{a a}$ and $X^{a a}$ to denote consumption, labor and input 
choices in this scenario. In each period $t$ the person chooses $L_{t}^{a a}$ to satisfy $\frac{U_{l}^{\prime}\left(c_{t}^{a a}, \bar{L}-L_{t}^{a a}, 0\right)}{U_{c}^{\prime}\left(c_{t}^{a a}, \bar{L}-L_{t}^{a a}, 0\right)}=$ $p_{t} F_{L}^{\prime}\left(\theta, L_{t}^{a a}, X_{t-1}^{a a}\right)$ taking $X_{t-1}^{a a}$ as given, and he chooses agricultural investment $X_{t}^{a a}$ to satisfy $\frac{p_{t+1}}{q_{t}} F_{X}^{\prime}\left(\theta, L_{t+1}^{a a}, X_{t}^{a a}\right)=1+r$, taking expected $p_{t+1}$ and $L_{t+1}^{a a}$ as given.

Now, taking levels of $c^{a a}, L^{a a}$ and $X^{a a}$ as given, we can look at people' decision to engage in illicit activities. People will engage in illicit activities if and only if

$$
w_{t}-\frac{\rho f}{1+r} \geq \frac{U_{l}^{\prime}\left(c_{t}^{a a}, \bar{L}-L_{t}^{a a}, 0\right)}{U_{c}^{\prime}\left(c_{t}^{a a}, \bar{L}-L_{t}^{a a}, 0\right)}+\sigma \frac{-U_{\sigma L^{m}}^{\prime}\left(c_{t}^{a a}, \bar{L}-L_{t}^{a a}, 0\right)}{U_{c}^{\prime}\left(c_{t}^{a a}, \bar{L}-L_{t}^{a a}, 0\right)}
$$

which says the expected returns from illicit activities (wage minus the present value of expected punishment) must be higher than the highest possible marginal rate of substitution between leisure and consumption the person can achieve without engaging in illicit activities. Since $-U_{\sigma L^{m}}^{\prime} / U_{c}^{\prime}>0$, a rise in $\sigma$ means more people will drop out of illicit activities.

If condition 6 is satisfied and if $X_{t-1}>0$, the person then chooses $L_{t}^{m}$ and $L_{t}^{a}$ such that the marginal product of labor in agriculture equals his net marginal gains from illicit activities, which also equals his marginal rate of substitution between leisure and consumption: i.e. conditions 1 and 2 will be satisfied. Notice that $L_{t}^{m}$ may not always be positive. People will not engage in illicit activities if any or all three of the following happens: (1) $w_{t}$ is very low relative to price level $p_{t}$ and potential punishment $\rho f ;(2)$ productivity in agriculture $\theta$ is very high; and (3) the degree of aversion to illicit activities $\sigma$ is very high.

Now we come back to the level of $X_{t}$. People choose inputs for period $t+1$ at time $t$ with the correct expectation of next period's prices and wages. Each person chooses $X_{t}$ such that investment returns in agriculture and alternative assets are equalized: i.e. condition 3 $\frac{p_{t+1}}{q_{t}} F_{X}^{\prime}\left(\theta, L_{t+1}^{a}, X_{t}\right)=1+r$ will be satisfied.

\section{Comparative Statics}

First, we define the elasticities of illicit labor to the parameters or variables most likely to be affected by the intervention, $\theta, X, \rho f$ and $\sigma: \varepsilon_{\theta}=\frac{d L_{m}}{d \theta} / \frac{L_{m}}{\theta}, \varepsilon_{X}=\frac{d L_{m}}{d X} / \frac{L_{m}}{X}, \varepsilon_{\rho f}=\frac{d L_{m}}{d \rho f} / \frac{L_{m}}{\rho f}$, 
, $\varepsilon_{\sigma}=\frac{d L_{m}}{d \sigma} / \frac{L_{m}}{\sigma}$. We are also interested in the responsiveness of labor supply to the illicit wage.

$w_{t}$

We focus on the case where, as wages $w_{t}$ or the marginal product of labor $p_{t} F_{L}^{\prime}(t)$ increases, the substitution effect is greater than the income effect on hours (a reasonable assumption when both wealth and income are relatively low). If the illicit wage rises, people will engage in illicit activities as $w_{t}$ surpasses their threshold wage level defined in inequality (6). For those who already engage in both activities, $L_{t}^{m}$ rises and $L_{t}^{a}$ falls so that equations (1) and 2 are satisfied. The ratio $\frac{L^{m}}{L^{m}+L^{a}}$ rises-people are more inclined to engage in illicit activities as $w$ rises. Then the right hand side of (3) falls (since labor and other inputs are complements), which means the optimal level of $X_{t-1}$ must fall in order to satisfy equations (3) and (4). Since we assumed substitution effects always dominate income effects, total hours $L_{t}^{a}+L_{t}^{m}$ should rise. Total earnings $y_{t} \equiv p_{t} F\left(\theta, L_{t}^{a}, X_{t-1}\right)+w_{t} L_{t}^{m}$ would rise as $w_{t}$ rises because equilibrium returns to both sectors are now higher. Therefore, $\frac{\partial L_{t}^{a}}{\partial w_{t}}<0, \frac{\partial L_{t}^{m}}{\partial w_{t}}>0, \frac{\partial X_{t-1}}{\partial w_{t}}<0$, $\frac{\partial l_{t}}{\partial w_{t}}<0$ and $\frac{\partial y_{t}}{\partial w_{t}}>0$. It's worth noting that because of equations (3) and (4) the returns to investment in inputs will not change as $w_{t}$ changes, despite the changes in $L^{a}$ and $X$.

$\rho f$

In the absence or risk and uncertainty the effect of an increase in $\rho f$ will be the same as the effect of a fall in $w_{t}$. Future punishment essentially acts as a monetary penalty to wages in the illicit sector. Therefore, an increase in $\rho f$ will increase agricultural hours and earnings from agriculture, but reduce hours in illicit activities, total hours, and total earnings: , $\frac{\partial L_{t}^{a}}{\partial \rho f}>0, \frac{\partial L_{t}^{m}}{\partial \rho f}<0$ (i.e. $\left.\varepsilon_{\rho f}<0\right), \frac{\partial X_{t-1}}{\partial \rho f}>0, \frac{\partial l_{t}}{\partial \rho f}>0$ and $\frac{\partial y_{t}}{\partial \rho f}<0$. 
As $\sigma$ rises, we will see a change in illicit work on the extensive margin: fewer people will engage in these activities since a higher $\sigma$ implies a higher right hand side in inequality (6). For those who already engage in both activities, to keep equation (2) an identity, the optimal level of $L_{t}^{m}$ must fall and $L_{t}^{a}$ must rise. The ratio $\frac{L^{m}}{L^{m}+L^{a}}$ falls-people take time away from illicit activities and put more time into agriculture production. $X_{t-1}$ then rises because of the rise in $L_{t}^{a}$. The effect on hours and total earnings is less obvious. But holding everything else constant (i.e. marginal utility of consumption and leisure, wages, prices and productivity), an increase in $\sigma$ will lead to a fall in $w_{t}+\sigma \frac{U_{\sigma L^{m}}^{\prime}(t)}{U_{c}^{\prime}(t)}$, which means a lower level of both $\frac{U_{l}^{\prime}(t)}{U_{c}^{\prime}(t)}$ and marginal productivity of labor $p_{t} F_{L}^{\prime}(t)$ in equilibrium. Even though earnings from agriculture will be higher, the first order effect of $\sigma$ on $L_{t}^{m}$ dominates its effects on $L_{t}^{a}$ , which means $c_{t}$ and $y_{t}$ will be lower in equilibrium, and $l_{t}$ higher. Therefore, $\frac{\partial L_{t}^{a}}{\partial \sigma}>0$, $\frac{\partial L_{t}^{m}}{\partial \sigma}<0, \varepsilon_{\sigma}<0, \frac{\partial X_{t-1}}{\partial \sigma}>0, \frac{\partial l_{t}}{\partial \sigma}>0$ and $\frac{\partial y_{t}}{\partial \sigma}<0$.

$\theta$

Now we consider the effect of an increase in the available agricultural technology $\theta$. On the extensive margin, fewer people will engage in illicit activities and more will engage in agriculture activities. ${ }^{41}$

On the intensive margin, for those who already engage in both activities, the effect of a rise in productivity level $\theta$ is ambiguous. Because of equations (3) and (4), the returns to investment in inputs will not change (at least so long as we don't have any financial constraints or risk). Input level $X$ would rise and labor-input ratio $\frac{L^{a}}{X}$ will fall. However, the direction of change in $L^{a}$ depends on the shape of production and utility functions as well as the person's wealth level. So do the effects on leisure and hours in illicit activities. Both

\footnotetext{
${ }^{41} \mathrm{~A}$ higher $\theta$ leads to a relatively large increase in $c^{a a}$ and an ambiguous but relatively small change in $l^{a a}$, which together implies a higher right hand side in inequality (6).This is intuitive: as productivity rises, agriculture alone can provide high levels of consumption and leisure for the person such that illicit activities do not seem attractive any more.
} 
earnings in agriculture and total earnings $y$ will rise. Consumption will rise. If agricultural production is very labor intensive (which is likely the case), then a rise in $\theta$ will lead to a rise in both $L^{a}$ and $p_{t} F_{L}^{\prime}(t)$, which means a higher level of $\frac{U_{L}^{\prime}(t)}{U_{c}^{\prime}(t)}$ in equilibrium, and therefore a lower level of leisure. The effect on $L^{m}$ depends on the sign of $U_{\sigma L^{m}}^{\prime}$. To sum up, $\frac{\partial X_{t-1}}{\partial \theta}>0$, $\frac{\partial y_{t}}{\partial \theta}<0$ for certain, and $\frac{\partial L_{t}^{a}}{\partial \theta}>0$ and $\frac{\partial l_{t}}{\partial \theta}<0$ if agriculture production is labor intensive and ambiguous otherwise.

Averaging the effect on both margins, a rise in $\theta$ leads to a fall in average $L^{m}$ and arise in $L^{a}$. Therefore, $\frac{L^{m}}{L^{m}+L^{a}}$ falls and $\varepsilon_{\theta}<0$. Note that an increase in $p_{t}$ (or decrease in $q_{t}$ ) would have similar effects as an increase in $\theta$.

$X_{t}$

Since input $X_{t}$ is a choice variable and there are no financial market imperfections, any intervention that provides $X_{t}$ will only have effects in the short-term: reducing returns in agriculture production to a level below $1+r$, increasing consumption and total earnings, and reducing hours in illicit activities. The short-term effects on $L^{a}$ and $l$ will depend on the labor intensity of the production function and how important leisure is in the utility function. However, in the long run, this capital will be divested and everything will go back to equilibrium levels. In the short run, $\frac{L^{m}}{L^{m}+L^{a}}$ falls and $\varepsilon_{X}<0$; in the long run, $\frac{L^{m}}{L^{m}+L^{a}}$ returns to its normal level and $\varepsilon_{X}=0$.

\section{C.3 The case of credit constraints without uncertainty}

We consider the simplest case of credit constraints where there is no borrowing whatsoever: $a_{t} \geq 0$. Equation (4) becomes $\frac{U_{c}^{\prime}(t)}{U_{c}^{\prime}(t+1)}=\delta(1+r)$ if $a_{t}>0$ and $\frac{U_{c}^{\prime}(t)}{U_{c}^{\prime}(t+1)}>\delta(1+r)$ if $a_{t}=0$. Combining this with(3), we have

$$
\frac{p_{t+1}}{q_{t}} F_{X}^{\prime}\left(\theta, L_{t+1}^{a}, X_{t}\right)=\max \left\{1+r, \frac{1}{\delta}\right\}
$$


This implies that fewer people with low wealth will engage in agriculture, and those that do will invest less in inputs if the credit constraint binds. Unlike the benchmark model, patience now matters for input decisions: the impatient will now under-invest in agriculture.

In a low wealth sample like ours, compared to the benchmark case, the credit constraint

leads to a lower level of investment $X$ for the impatient types whose $\delta<\frac{1}{1+r}$, fewer hours in agriculture (lower $L^{a}$ ), but more hours in illicit activities (higher $L^{m}$ ). Some low patience people will have to give up agriculture altogether because of the credit constraints. On average, $\frac{L^{m}}{L^{a}+L^{m}}$ will be higher than in the benchmark case.

Interventions in $\theta$ and $\sigma$ will have similar effects as in the benchmark case; $\varepsilon_{\theta}$ and $\varepsilon_{\sigma}$ will have the same signs as in the benchmark case. However, the magnitude of the effects change. A rise in $\theta$ will now have a smaller effect than in the benchmark case, because the credit constraint makes it harder for everyone to increase their investment in agriculture. On the contrary, a rise in $\sigma$ will now have a bigger effect than in the benchmark case, because the credit constraint makes illicit activities more attractive than in the benchmark case.

Perhaps most importantly, interventions in $X_{t}$ will now have long-term effects: inducing people to engage in agriculture activities, and increasing input investments for those who were credit constrained. $\varepsilon_{X}<0$ both in the long and in the short run. It is worth noting that in this case giving people $\Delta X_{t}$ amount of inputs should have the exact same effect as giving them a cash transfer of $q_{t} \Delta X_{t}$.

In other words, $\epsilon_{\sigma}<0, \varepsilon_{\theta}<0$ and $\varepsilon_{X}<0$; the magnitude of $\varepsilon_{\theta}$ and $\varepsilon_{\sigma}$ are lower than in the benchmark case; while $\varepsilon_{X}$ is higher.

\section{C.4 The case of credit constraints with uncertainty and incomplete insurance}

We now turn to credit constraints in the presence of uncertainty and risk aversion. For simplicity we assume there is no insurance market, and that the riskless asset remains riskless.

The first order conditions now become 


$$
\begin{aligned}
\mathbb{E}_{t-1}\left[U_{l}^{\prime}(t)\right] & =\mathbb{E}_{t-1}\left[U_{c}^{\prime}(t) p_{t} F_{L}^{\prime}(t)\right] \quad \text { if } L_{t}^{a}>0 \\
\mathbb{E}_{t-1}\left[U_{l}^{\prime}(t)\right]-\mathbb{E}_{t-1}\left[\sigma U_{\sigma L^{m}}^{\prime}(t)\right] & =\mathbb{E}_{t-1}\left[U_{c}^{\prime}(t) w_{t}\right]-\delta \mathbb{E}_{t}\left[U_{c}^{\prime}(t+1)\right] \text { ff if } L_{t}^{m}>0 \\
U_{c}^{\prime}(t) & =\delta \mathbb{E}_{t}\left[U_{c}^{\prime}(t+1) \frac{p_{t+1}}{q_{t}} F_{X}^{\prime}(t+1)\right] \quad \text { if } X_{t}>0 \\
U_{c}^{\prime}(t) & =\delta(1+r) \mathbb{E}_{t}\left[U_{c}^{\prime}(t+1)\right] \quad \text { if } a_{t+1}>0 \\
c_{t}+a_{t+1}+q_{t} X_{t} & =p_{t} F\left(\theta, L_{t}^{a}, X_{t-1}\right)+w_{t} L_{t}^{m}+(1+r) a_{t}
\end{aligned}
$$

Inequality (6), the threshold level of $w_{t}$ that people will engage in illicit activities, now becomes

$$
\begin{gathered}
\mathbb{E}_{t-1}\left[U_{c}^{\prime}\left(c_{t}^{a a}, \bar{L}-L_{t}^{a a}, 0\right) w_{t}\right]-\delta \mathbb{E}_{t}\left[U_{c}^{\prime}\left(c_{t+1}^{a a}, \bar{L}-L_{t+1}^{a a}, 0\right)\right] \rho f \geq \\
\mathbb{E}_{t-1}\left[U_{l}^{\prime}\left(c_{t}^{a a}, \bar{L}-L_{t}^{a a}, 0\right)\right]-\mathbb{E}_{t-1}\left[\sigma U_{\sigma L^{m}}^{\prime}\left(c_{t}^{a a}, \bar{L}-L_{t}^{a a}, 0\right)\right]
\end{gathered}
$$

and we have another equation for the returns of input investments under uncertainty

$$
\mathbb{E}_{t}\left[\frac{p_{t+1}}{q_{t}} F_{X}^{\prime}\left(\theta_{t+1}, L_{t+1}^{a}, X_{t}\right)\right]-(1+r)=-(1+r) \operatorname{Cov}_{t}\left(\frac{p_{t+1}}{q_{t}} F_{X}^{\prime}\left(\theta_{t+1}, L_{t+1}^{a}, X_{t}\right), S D_{t}\right)
$$

and

$$
(1+r)\left[1+\operatorname{Cov}_{t}\left(\frac{p_{t+1}}{q_{t}} \theta_{t+1} M, S D_{t}\right)\right] \leq \mathbb{E}_{t}\left[\frac{p_{t+1}}{q_{t}} \theta_{t+1} M\right]
$$

where $S D_{t}=\frac{\delta U_{1}^{\prime}(t+1)}{U_{1}^{\prime}(t)}$ is the stochastic discount factor.

Now input $X$ and hours $L^{m}$ and $L^{a}$ all depend both on the variance of returns in the two sectors and the level of initial wealth $a_{0}$. Those with high levels of wealth $a_{0}$ will turn away from both activities by reducing $X, L^{m}$ and $L^{a}$ and investing instead in other riskless assets $X$. $L^{m}$ and $L^{a}$ will all be lower than both the benchmark case and the credit constraint only case.

People with low levels of wealth (i.e. our sample) will not be able to live off savings alone, 
so they will have to invest more in both sectors by increasing $X, L^{m}$ and $L^{a}$ if both sectors are equally risky. Otherwise, if one of the sectors are less risky than the other, people will

invest more time in that sector. $\frac{L^{m}}{L^{a}+L^{m}}$ will be higher than in the case without uncertainty only if illicit activities are less risky than agriculture.

Importantly, interventions in $\theta$ will have greater effects than in the benchmark and credit constraint case, because an increase in $\theta$ now also makes agriculture relatively less risky. A rise in $\sigma$ will also have a bigger effect than without uncertainty, because risk aversion will reinforce the rise in aversion and further reduce hours in illicit activities. Inventions in $X_{t}$ will have a similar long-term effect as in the credit constraint only scenario. However, for the risk averse people the effect of $\Delta X_{t}$ will be greater than a cash transfer $q_{t} \Delta X_{t}$. The effects increase as the level of risk aversion increases, and also as the level of risk increase. Similarly, a change in either the probability or extent of punishment will have a bigger effect on hours and earnings: an increase in $\rho f$ will make illicit activity even more unattractive, as it reduces the expected returns to illicit activity while not reducing the risk of such activities.

In other words, $\epsilon_{\sigma}<0, \varepsilon_{\theta}<0, \varepsilon_{\rho f}<0$ and $\varepsilon_{X}<0$; the magnitude of all four elasticities will be higher than in the credit constraint without uncertainty case.

\section{Additional treatment effects analysis}

\section{D.1 ITT and TOT estimates with all index components}

Table D.1 reports intent-to-treat (ITT) impacts of the program on our measures of mercenary recruitment. Tables D.2 to D.7 expand the family indices that appear in the main paper. Finally, Tables D.12 and D.13 expand the number of outcomes analyzed for the marginal impact of package choice. 
Table D.1: Intent to treat impacts on mercenary recruitment activities

\begin{tabular}{lccc}
\hline & Control & \multicolumn{2}{c}{ ITT estimate } \\
\cline { 3 - 4 } Outcome & Mean & Coeff. & SE \\
& $(1)$ & $(2)$ & $(3)$ \\
\hline Mobilization activities/attitudes (z-score) & 0.09 & -0.156 & {$[0.065]^{* *}$} \\
Direct recruitment activities (0-12) & 0.94 & -0.183 & {$[0.097]^{*}$} \\
Talked to a commander in last 3 months & 0.45 & -0.083 & {$[0.037]^{* *}$} \\
Would go if called to fight for tribe & 0.05 & -0.012 & {$[0.011]$} \\
Has been approached about going to CI & 0.07 & 0.001 & {$[0.017]$} \\
Would go to CI for $\$ 250$ & 0.01 & -0.005 & {$[0.008]$} \\
Would go to CI for $\$ 500$ & 0.03 & -0.007 & {$[0.010]$} \\
Would go to CI for $\$ 1000$ & 0.08 & -0.032 & {$[0.016]^{*}$} \\
Will move towards CI border area & 0.10 & -0.017 & {$[0.020]$} \\
Invited to secret meeting on going to CI & 0.04 & 0.003 & {$[0.013]$} \\
Attended secret meeting on going to CI & 0.03 & -0.010 & {$[0.009]$} \\
Was promised money to go to CI & 0.03 & 0.001 & {$[0.011]$} \\
Willing to fight if war breaks out in CI & 0.04 & -0.014 & {$[0.012]$} \\
Has plans to go to CI in the next month & 0.01 & -0.009 & {$[0.007]$} \\
Indirect recruitment measures (0-4) & 1.48 & -0.121 & {$[0.062]^{*}$} \\
Talks about the CI violence with friends & 0.68 & -0.035 & {$[0.034]$} \\
Has a partisan preference in CI & 0.66 & -0.089 & {$[0.034]^{* * *}$} \\
Knows people who went to CI to fight & 0.10 & -0.016 & {$[0.016]$} \\
Knows people given money to go to CI & 0.04 & 0.020 & {$[0.013]$} \\
\hline
\end{tabular}

Notes: This table includes all questions used in a "mobilization risk" survey module.Standard errors are robust and clustered at the village level.

$* * * \mathrm{p}<0.01,{ }^{* *} \mathrm{p}<0.05, * \mathrm{p}<0.1$ 


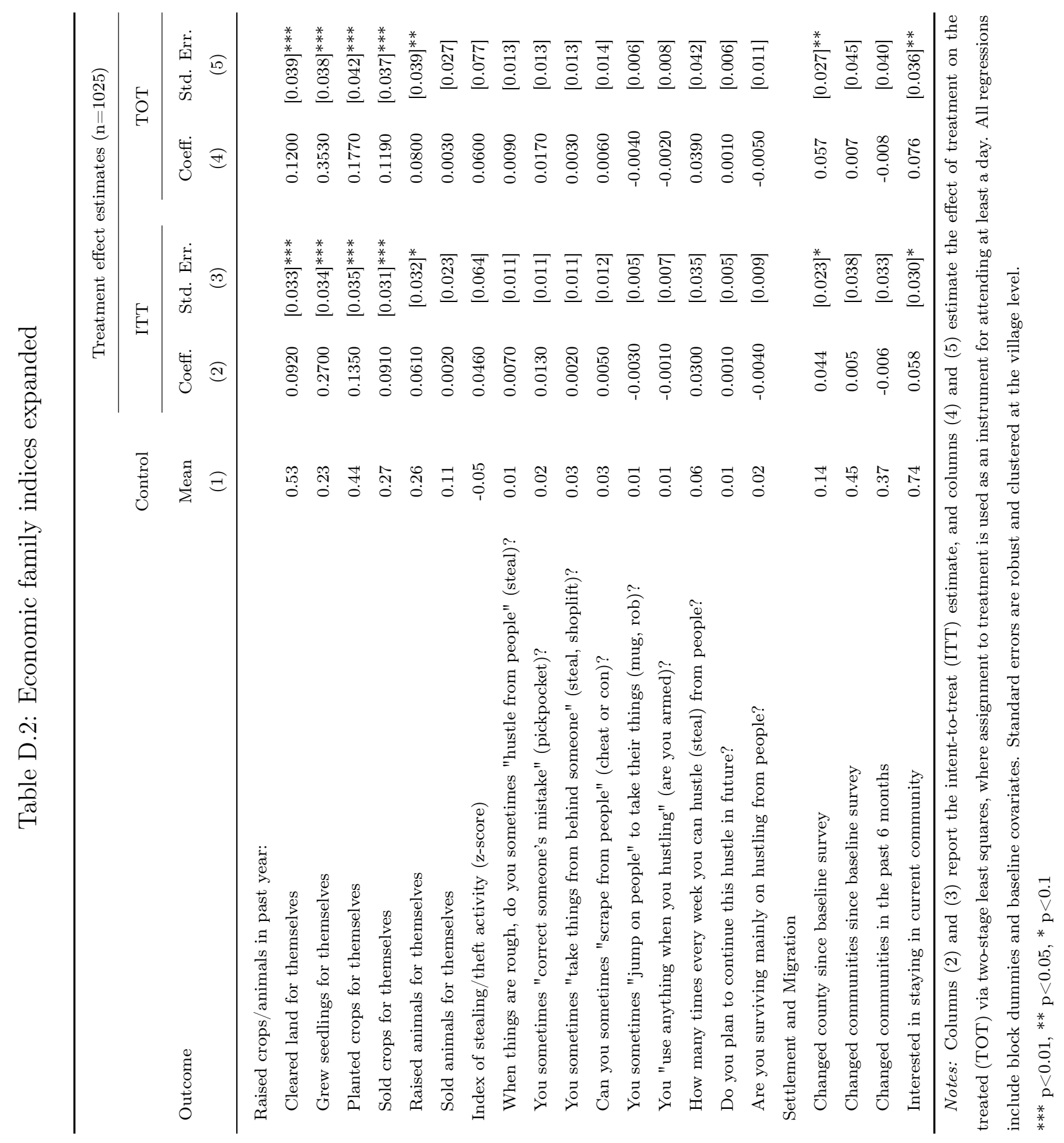


Table D.3: Peer group index expanded

\begin{tabular}{|c|c|c|c|c|c|}
\hline \multirow[b]{3}{*}{ Outcome } & \multirow{3}{*}{$\begin{array}{l}\text { Control } \\
\text { Mean } \\
(1)\end{array}$} & \multicolumn{4}{|c|}{ Treatment effect estimates $(\mathrm{N}=1025)$} \\
\hline & & \multicolumn{2}{|c|}{ ITT } & \multicolumn{2}{|c|}{ TOT } \\
\hline & & $\begin{array}{l}\text { Coeff. } \\
(2)\end{array}$ & $\begin{array}{l}\text { SE } \\
(3)\end{array}$ & $\begin{array}{l}\text { Coeff. } \\
(4)\end{array}$ & $\begin{array}{l}\mathrm{SE} \\
(5)\end{array}$ \\
\hline \multicolumn{6}{|l|}{ Are your closest friends...? } \\
\hline Interested in school & 0.78 & -0.002 & {$[0.027]$} & -0.003 & {$[0.032]$} \\
\hline Participate in community meetings & 0.96 & -0.014 & {$[0.015]$} & -0.018 & {$[0.018]$} \\
\hline Go to church or mosque & 0.91 & -0.015 & {$[0.021]$} & -0.019 & {$[0.025]$} \\
\hline Have a business or a job & 0.58 & 0.055 & {$[0.030]^{*}$} & 0.072 & {$[0.035]^{* *}$} \\
\hline Save money regularly & 0.77 & 0.043 & {$[0.030]$} & 0.056 & {$[0.036]$} \\
\hline Give you advice & 0.97 & -0.015 & {$[0.012]$} & -0.019 & {$[0.014]$} \\
\hline Work hard & 0.97 & 0.000 & {$[0.010]$} & 0.000 & {$[0.013]$} \\
\hline \multicolumn{6}{|l|}{ Share with you if they have money } \\
\hline and you don't & 0.95 & -0.024 & {$[0.016]$} & -0.032 & {$[0.019]^{*}$} \\
\hline \multicolumn{6}{|l|}{ Make you feel better when you are } \\
\hline feeling badly & 0.90 & 0.032 & {$[0.023]$} & 0.042 & {$[0.027]$} \\
\hline Can be trusted to guard your valuables & 0.87 & 0.003 & {$[0.020]$} & 0.003 & {$[0.024]$} \\
\hline Get drunk regularly & 0.26 & -0.004 & {$[0.030]$} & -0.005 & {$[0.036]$} \\
\hline Beg for money from strangers & 0.06 & 0.013 & {$[0.017]$} & 0.017 & {$[0.020]$} \\
\hline Use drugs & 0.06 & -0.010 & {$[0.016]$} & -0.014 & {$[0.020]$} \\
\hline Gamble & 0.06 & 0.001 & {$[0.019]$} & 0.002 & {$[0.023]$} \\
\hline Steal other people's property & 0.03 & 0.003 & {$[0.011]$} & 0.004 & {$[0.013]$} \\
\hline Break and enter houses and businesses & 0.01 & 0.004 & {$[0.010]$} & 0.006 & {$[0.012]$} \\
\hline Do armed robbery/mugging & 0.00 & -0.003 & {$[0.007]$} & -0.003 & {$[0.008]$} \\
\hline $\begin{array}{l}\text { Often have small conflicts with } \\
\text { authorities }\end{array}$ & 0.22 & -0.011 & {$[0.030]$} & -0.015 & {$[0.035]$} \\
\hline $\begin{array}{l}\text { Often have major conflicts with the } \\
\text { authorities }\end{array}$ & 0.05 & 0.018 & {$[0.014]$} & 0.024 & {$[0.017]$} \\
\hline
\end{tabular}

Notes: See Table D.2. 
Table D.4: Social and family support family indices expanded

\begin{tabular}{|c|c|c|c|c|c|}
\hline \multirow[b]{3}{*}{ Outcome } & \multirow{3}{*}{$\begin{array}{l}\text { Control } \\
\text { Mean } \\
(1)\end{array}$} & \multicolumn{4}{|c|}{ Treatment effect estimates $(\mathrm{N}=1025)$} \\
\hline & & \multicolumn{2}{|c|}{ ITT } & \multicolumn{2}{|c|}{ TOT } \\
\hline & & $\begin{array}{l}\text { Coeff. } \\
(2)\end{array}$ & $\begin{array}{l}\text { SE } \\
(3)\end{array}$ & $\begin{array}{l}\text { Coeff. } \\
(4)\end{array}$ & $\begin{array}{l}\mathrm{SE} \\
(5)\end{array}$ \\
\hline $\begin{array}{l}\text { Index of social support in last mont } \\
\text { (z-score) }\end{array}$ & -0.06 & 0.144 & {$[0.072]^{* *}$} & 0.188 & {$[0.085]^{* *}$} \\
\hline $\begin{array}{l}\text { Anyone joked with you to make you } \\
\text { happy? }\end{array}$ & 1.41 & 0.142 & {$[0.076]^{*}$} & 0.186 & {$[0.092]^{* *}$} \\
\hline $\begin{array}{l}\text { Anybody help take care of your } \\
\text { things/family? }\end{array}$ & 1.71 & 0.062 & {$[0.082]$} & 0.082 & {$[0.098]$} \\
\hline $\begin{array}{l}\text { Anybody help you with your work? } \\
\text { You shared your feelings and they }\end{array}$ & 1.10 & 0.099 & [0.063] & 0.130 & {$[0.074]^{*}$} \\
\hline listened? & 1.59 & 0.028 & {$[0.061]$} & 0.037 & {$[0.073]$} \\
\hline $\begin{array}{l}\text { Anybody sat with you when you } \\
\text { feeling lonely? }\end{array}$ & 1.38 & 0.022 & {$[0.068]$} & 0.029 & {$[0.081]$} \\
\hline $\begin{array}{l}\text { Anybody helped you to make your } \\
\text { way through life? }\end{array}$ & 0.99 & 0.030 & {$[0.061]$} & 0.039 & {$[0.073]$} \\
\hline $\begin{array}{l}\text { Anybody lent you things beside } \\
\text { money? }\end{array}$ & 0.67 & 0.163 & {$[0.062]^{* * *}$} & 0.213 & {$[0.074]^{* * *}$} \\
\hline Anyone lent or gave you money? & 0.55 & 0.011 & {$[0.066]$} & 0.014 & {$[0.080]$} \\
\hline Index of family relations (z-score) & -0.00 & 0.101 & {$[0.062]$} & 0.133 & {$[0.075]^{*}$} \\
\hline See members of your family often? & 2.06 & 0.114 & {$[0.062]^{*}$} & 0.149 & {$[0.076]^{* *}$} \\
\hline Do you attend family meetings? & 1.50 & 0.127 & {$[0.080]$} & 0.166 & {$[0.097]^{*}$} \\
\hline Your family concerned about you? & 2.40 & 0.029 & {$[0.053]$} & 0.037 & {$[0.063]$} \\
\hline Do they advise or encourage you? & 2.22 & -0.007 & {$[0.063]$} & -0.010 & {$[0.075]$} \\
\hline Family members help you when you & & & & & \\
\hline are stuck? & 1.36 & 0.152 & {$[0.071]^{* *}$} & 0.198 & {$[0.087]^{* *}$} \\
\hline You have disputes in your family? & 2.68 & -0.027 & {$[0.044]$} & -0.036 & {$[0.053]$} \\
\hline You caused trouble for them? & 2.87 & -0.017 & {$[0.032]$} & -0.022 & {$[0.038]$} \\
\hline
\end{tabular}

Notes: See Table D.2. 
Table D.5: Antisocial behaviors family index expanded

\begin{tabular}{|c|c|c|c|c|c|}
\hline \multirow[b]{3}{*}{ Outcome } & \multirow{3}{*}{$\begin{array}{l}\text { Control } \\
\text { Mean } \\
(1)\end{array}$} & \multicolumn{4}{|c|}{ Treatment effect estimates $(\mathrm{N}=1025)$} \\
\hline & & \multicolumn{2}{|c|}{ ITT } & \multicolumn{2}{|c|}{ TOT } \\
\hline & & $\begin{array}{l}\text { Coeff. } \\
(2)\end{array}$ & $\begin{array}{l}\text { SE } \\
(3)\end{array}$ & $\begin{array}{l}\text { Coeff. } \\
(4)\end{array}$ & $\begin{array}{l}\text { SE } \\
(5)\end{array}$ \\
\hline \multicolumn{6}{|l|}{ In the last month... } \\
\hline Was unable to control your anger & 0.48 & 0.044 & {$[0.046]$} & 0.058 & {$[0.056]$} \\
\hline Was quick to react against others & 0.19 & 0.059 & {$[0.042]$} & 0.077 & {$[0.050]$} \\
\hline Said cruel things to other people & 1.36 & -0.033 & {$[0.076]$} & -0.043 & {$[0.091]$} \\
\hline Let other people see your frustration & 0.49 & 0.111 & {$[0.057]^{*}$} & 0.146 & {$[0.068]^{* *}$} \\
\hline Intentionally destroyed property & 0.05 & -0.003 & {$[0.020]$} & -0.004 & {$[0.024]$} \\
\hline Refused to take advice & 0.14 & 0.022 & {$[0.036]$} & 0.029 & {$[0.044]$} \\
\hline Cheated other people & 0.13 & 0.034 & {$[0.037]$} & 0.044 & {$[0.044]$} \\
\hline Had major arguments with others & 0.07 & 0.000 & {$[0.018]$} & 0.001 & {$[0.022]$} \\
\hline "Held your heart" when angry & 0.94 & 0.036 & {$[0.068]$} & 0.047 & {$[0.081]$} \\
\hline Threatened people & 0.10 & 0.002 & {$[0.030]$} & 0.002 & {$[0.035]$} \\
\hline $\begin{array}{l}\text { Took other people's things without } \\
\text { asking }\end{array}$ & 0.03 & 0.046 & {$[0.019]^{* *}$} & 0.060 & {$[0.023]^{* * *}$} \\
\hline In the past 6 months.... & & & & & \\
\hline Had a fight or angry dispute & 0.70 & 0.000 & {$[0.115]$} & 0.000 & {$[0.138]$} \\
\hline $\begin{array}{l}\text { Had a confrontations with leaders or } \\
\text { police }\end{array}$ & 0.64 & -0.179 & {$[0.148]$} & -0.234 & {$[0.178]$} \\
\hline
\end{tabular}

Notes: See Table D.2. 
Table D.6: Approval for use of violence family index expanded

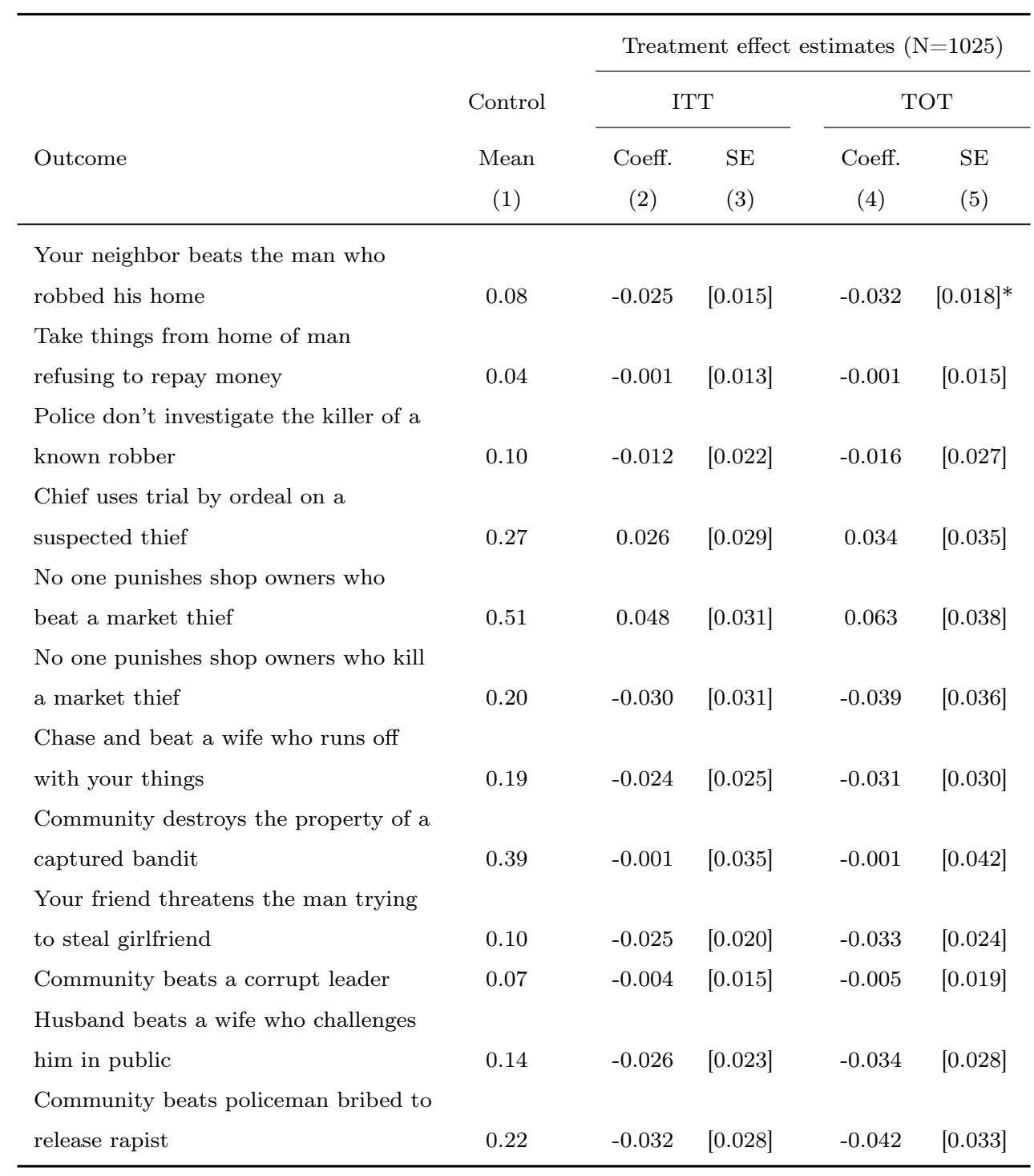

Notes: See Table D.2. 
Table D.7: Community participation family index expanded

\begin{tabular}{|c|c|c|c|c|c|}
\hline \multirow[b]{3}{*}{ Outcome } & \multirow{3}{*}{$\begin{array}{l}\text { Control } \\
\text { Mean } \\
\text { (1) }\end{array}$} & \multicolumn{4}{|c|}{ Treatment effect estimates $(\mathrm{N}=1025)$} \\
\hline & & \multicolumn{2}{|c|}{ ITT } & \multicolumn{2}{|c|}{ TOT } \\
\hline & & $\begin{array}{l}\text { Coeff. } \\
(2)\end{array}$ & $\begin{array}{l}\text { SE } \\
(3)\end{array}$ & $\begin{array}{l}\text { Coeff. } \\
(4)\end{array}$ & $\begin{array}{l}\text { SE } \\
(5)\end{array}$ \\
\hline Number of groups involved in & 5.36 & 0.288 & {$[0.142]^{* *}$} & 0.376 & {$[0.168]^{* *}$} \\
\hline Is a group leader & 0.48 & 0.053 & {$[0.033]$} & 0.069 & {$[0.039]^{*}$} \\
\hline Is a community leader & 0.29 & -0.019 & {$[0.028]$} & -0.024 & {$[0.034]$} \\
\hline Attended community meetings & 0.94 & -0.017 & {$[0.020]$} & -0.022 & {$[0.025]$} \\
\hline Believes can do things to improve & & & & & \\
\hline community & 0.89 & 0.018 & {$[0.018]$} & 0.024 & {$[0.021]$} \\
\hline Volunteered for road clearing & 0.78 & 0.007 & {$[0.030]$} & 0.009 & {$[0.036]$} \\
\hline Contributed to care of community & & & & & \\
\hline water sources & 0.67 & 0.021 & {$[0.036]$} & 0.027 & {$[0.043]$} \\
\hline Contributed to other public facilities & 0.63 & 0.010 & {$[0.035]$} & 0.013 & {$[0.042]$} \\
\hline Is a "big man" in community & 0.35 & 0.003 & {$[0.034]$} & 0.004 & {$[0.041]$} \\
\hline Organizes new groups & 0.50 & 0.009 & {$[0.038]$} & 0.011 & {$[0.045]$} \\
\hline People often come to you for advice & 0.38 & 0.014 & {$[0.033]$} & 0.018 & {$[0.039]$} \\
\hline $\begin{array}{l}\text { Community members come to you to } \\
\text { solve disputes }\end{array}$ & 0.28 & 0.011 & {$[0.033]$} & 0.015 & {$[0.039]$} \\
\hline $\begin{array}{l}\text { Your friends come to you to solve } \\
\text { disputes }\end{array}$ & 0.83 & 0.011 & {$[0.031]$} & 0.014 & {$[0.038]$} \\
\hline
\end{tabular}

Notes: See Table D.2. 


\section{D.2 ITT and TOT effects on secondary outcomes}

Table D.8: Other outcomes

\begin{tabular}{|c|c|c|c|c|c|}
\hline \multirow[b]{3}{*}{ Outcome } & \multirow{3}{*}{$\begin{array}{l}\text { Control } \\
\text { Mean } \\
(1)\end{array}$} & \multicolumn{4}{|c|}{ Treatment effect estimates $(\mathrm{N}=1025)$} \\
\hline & & \multicolumn{2}{|c|}{ ITT } & \multicolumn{2}{|c|}{ TOT } \\
\hline & & $\begin{array}{l}\text { Coeff. } \\
(2)\end{array}$ & $\begin{array}{l}\mathrm{SE} \\
(3)\end{array}$ & $\begin{array}{c}\text { Coeff. } \\
(4)\end{array}$ & $\begin{array}{l}\text { SE } \\
(5)\end{array}$ \\
\hline $\begin{array}{l}\text { Obtained more schooling or } \\
\text { skills training }\end{array}$ & 0.207 & 0.021 & {$[0.035]$} & 0.016 & {$[0.029]$} \\
\hline Attention span index & 5.167 & -0.143 & {$[0.116]$} & -0.109 & {$[0.095]$} \\
\hline Working memory index & 2.218 & -0.128 & {$[0.138]$} & -0.098 & {$[0.114]$} \\
\hline Substance abuse index (0-3) & 0.790 & -0.088 & {$[0.049]^{*}$} & -0.067 & {$[0.041]$} \\
\hline Has partner & 0.936 & -0.017 & {$[0.020]$} & -0.013 & {$[0.016]$} \\
\hline Living with partner & 0.620 & 0.029 & {$[0.035]$} & 0.022 & [0.029] \\
\hline Risky sex index (0-4) & 1.064 & -0.099 & {$[0.111]$} & -0.076 & {$[0.092]$} \\
\hline Partner abuse index $(0-4)$ & 0.718 & -0.120 & {$[0.082]$} & -0.092 & [0.069] \\
\hline Mental health issues index (0-72) & 15.840 & -0.329 & {$[0.932]$} & -0.251 & {$[0.778]$} \\
\hline $\begin{array}{l}\text { Standardized index of } \\
\text { appearance at endline }\end{array}$ & 0.078 & -0.164 & {$[0.079]^{* *}$} & -0.126 & {$[0.066]^{*}$} \\
\hline Risk appetite, z-score & 0.133 & 0.006 & {$[0.076]$} & 0.005 & {$[0.063]$} \\
\hline Self control index, z-score & -0.053 & 0.037 & {$[0.075]$} & 0.028 & {$[0.063]$} \\
\hline
\end{tabular}

Notes: See Table D.2.

The attention span and working memory measures are constructed based on the digit recall module in the endline survey. The risk appetite and self control indices are based on selfreported attitudes and decisions in hypothetical scenarios. We did not believe that the program would change these four measures and viewed them as time-invariant characteristics. The rest of the outcomes are secondary ones measured in the endline survey.

\section{D.3 Robustness and sensitivity analysis}

Robustness to model choice and attrition Results in the main paper are generally robust to different models and missing data assumptions. Table D.9 reports sensitivity analysis for key outcomes. Column 1 replicates TOT estimates from Tables 3 to 7 in the main paper. Column 2 reports TOT without baseline covariates. Column 3 reports the same 
TOT estimates as in Column 1 but without clustering at the village level. Column 4 uses an alternate instrument for assignment to treatment - instead of counting the first $m$ men in each block as assigned to treatment up until the that block's quota $b$ is filled (so that $m \geq b$ ), the results in Column 4 do not count the $m>b$ men as assigned to treatment (rather, they are non-compliant). ${ }^{42}$

In general the qualitative conclusions are the same. Omitting covariates or using the alternate instrument slightly reduces the statistical significance of some effects, as one would expect.

Columns 5 to 7 consider whether our treatment effects could be the result of selective attrition. We estimate bounds by imputing outcome values for unfound individuals at different points of the observed outcome distribution, focusing on the cases that reduce program impacts. For positive outcomes we impute the observed mean plus $x$ standard deviations of the distribution for the control group, and for the treatment group we impute the observed treatment mean minus $x$ standard deviations of the distribution. We calculate estimates for $x=0.1,0.25$, and 0.5 . Note these imply large systematic differences between the missing treatment and control members. All treatment effects in are robust to $x=0.1$ and the majority are still robust to $x=0.25$. The sign on treatment is preserved when $x=0.5$.

Robustness of mercenary recruitment index We also consider permutations of the mercenary recruitment index in Table D.10. The table shows that the TOT estimate on the full index is robust to excluding various components, or to including an indictor for being physically found by our survey at endline in a border area (which is rare). The statistical significance of the treatment effect falls if we exclude all indirect proxies and "talked to a commander" but still has a similar sign and magnitude.

\footnotetext{
${ }^{42}$ This increases noise and estimates a different local average treatment effect than in Column (1), but avoids the small risk that the marginal person selected into treatment assignment in each is endogenously a more compliant type. The quota was usually $50 \%$ of the men registered in the block, whereas on average $57 \%$ were assigned to treatment using our ordered assignment method. Ideally we would use this $57 \%$ average as the instrument, counting people as assigned if they were in the first $57 \%$ of the block order, but we do not have the historical ranking in every block to do so.
} 


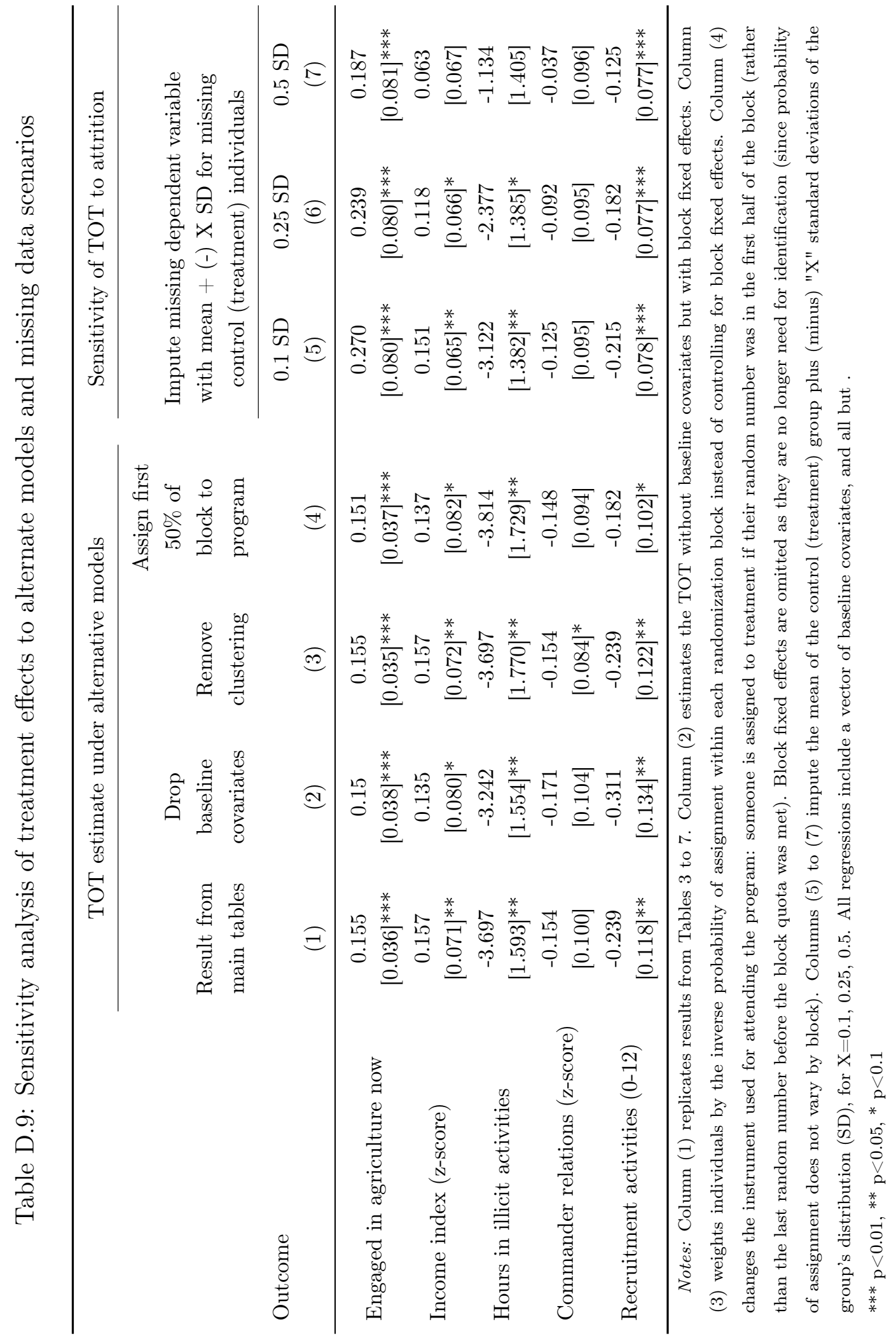


Table D.10: Program impacts on mercenary recruitment proxies

\begin{tabular}{lcccc}
\hline \multirow{2}{*}{ Outcome } & Control & \multicolumn{2}{c}{ TOT estimate } \\
\cline { 2 - 5 } & Mean & Coeff. & SE \\
& $(1)$ & $(2)$ & $(3)$ \\
\hline All recruitment interest/actions (0-16) & 2.41 & -0.397 & {$[0.154]^{* * *}$} \\
All, excluding "talked to a commander" (0-15) & 1.97 & -0.289 & {$[0.145]^{* *}$} \\
All, excluding "partisan preference" (0-15) & 2.86 & -0.506 & {$[0.173]^{* * *}$} \\
All, excluding "talked to a commander" and "partisan preference (0-14) & 2.41 & -0.397 & {$[0.154]^{* * *}$} \\
Direct only (0-12) & 0.94 & -0.239 & {$[0.118]^{* *}$} \\
Direct only, including "found in border town at endline" (0-13) & 0.94 & -0.233 & {$[0.117]^{* *}$} \\
$\quad$ Found in border town at endline & 0.00 & 0.007 & {$[0.006]$} \\
Direct only, excluding "talked to a commander" (0-11) & 0.49 & -0.131 & {$[0.103]$} \\
Direct only, excluding "would go to CI for $\$ 1000 " ~(0-11)$ & 0.86 & -0.198 & {$[0.109]^{*}$} \\
\hline
\end{tabular}

Notes: Columns (2)-(3) report the the effect of treatment on the treated (TOT) via two-stage least squares.

Regressions include block dummies and baseline covariates. Standard errors are clustered at the village level. See

Appendix D.1 for ITT results.

$* * * \mathrm{p}<0.01,{ }^{* *} \mathrm{p}<0.05, * \mathrm{p}<0.1$

Robustness of package choice estimates The estimates of the impact of in-kind inputs in Section 6.3 require an assumption of selection on observables (conditional unconfoundedness). We examine the sensitivity of our estimates to violations of this assumption using a technique proposed by Guido Imbens. ${ }^{43}$ We illustrate the sensitivity in Figure D.1 for two dependent variables: the index of mercenary recruitment interest and actions, and the hours per week of illicit work. Any unobserved confounder must be correlated with both the dependent variable and treatment assignment (in this case, the choice of animals as a package). The curve in each figure represents all combinations of correlation between an unobservable variable and the outcome (vertical axis) and animal choice (horizontal axis) that would reduce the observed treatment effect by half. The axes represent the hypothetical increase in partial R-squared that would result from observing this unobserved covariate and including it in a regression with either the outcome or the treatment as the dependent variable. The curve represents a threshold. Any covariate that laid to the right of the curve

\footnotetext{
${ }^{43}$ Imbens, Guido W., "Sensitivity to Exogeneity Assumptions in Program Evaluation", The American Economic Review 93 (2003), pp. 126-32. 2
} 
would indicate that our conditional unconfoundedness assumption is highly suspect.

How do we know where the unobservables lie? We do not, of course, but we can benchmark them against observed covariates. The + signs indicate the partial R-squared added by our observed covariates. We focus on only a handful of key covariates, and test classes of covariates (e.g. all economic performance measures) since dropping just one of a large class (e.g. income but not assets and work hours) would by construction have a low partial R-squared. The covariates include region fixed effect.

We see that entire classes of covariates, such as regional covariates or all economic or all social variables, have little influence on our treatment effects. For an unobserved covariate to bias our results, it must be wholly unlike other covariates we observe. We judge this to be unlikely given the richness of our data. 
Figure D.1: Sensitivity of the effect of animal choice to unobservables

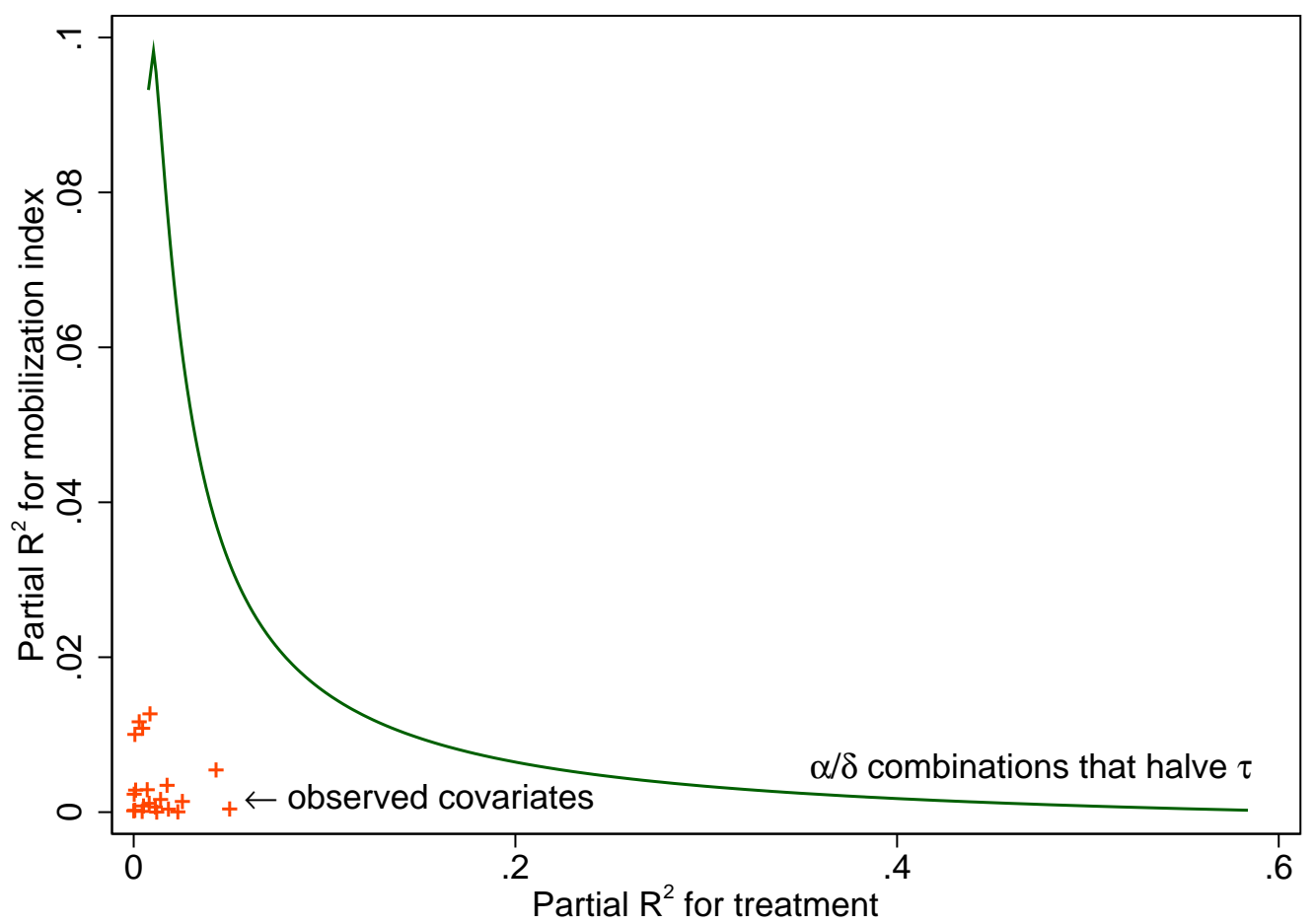

(a) All recruitment interest/actions index

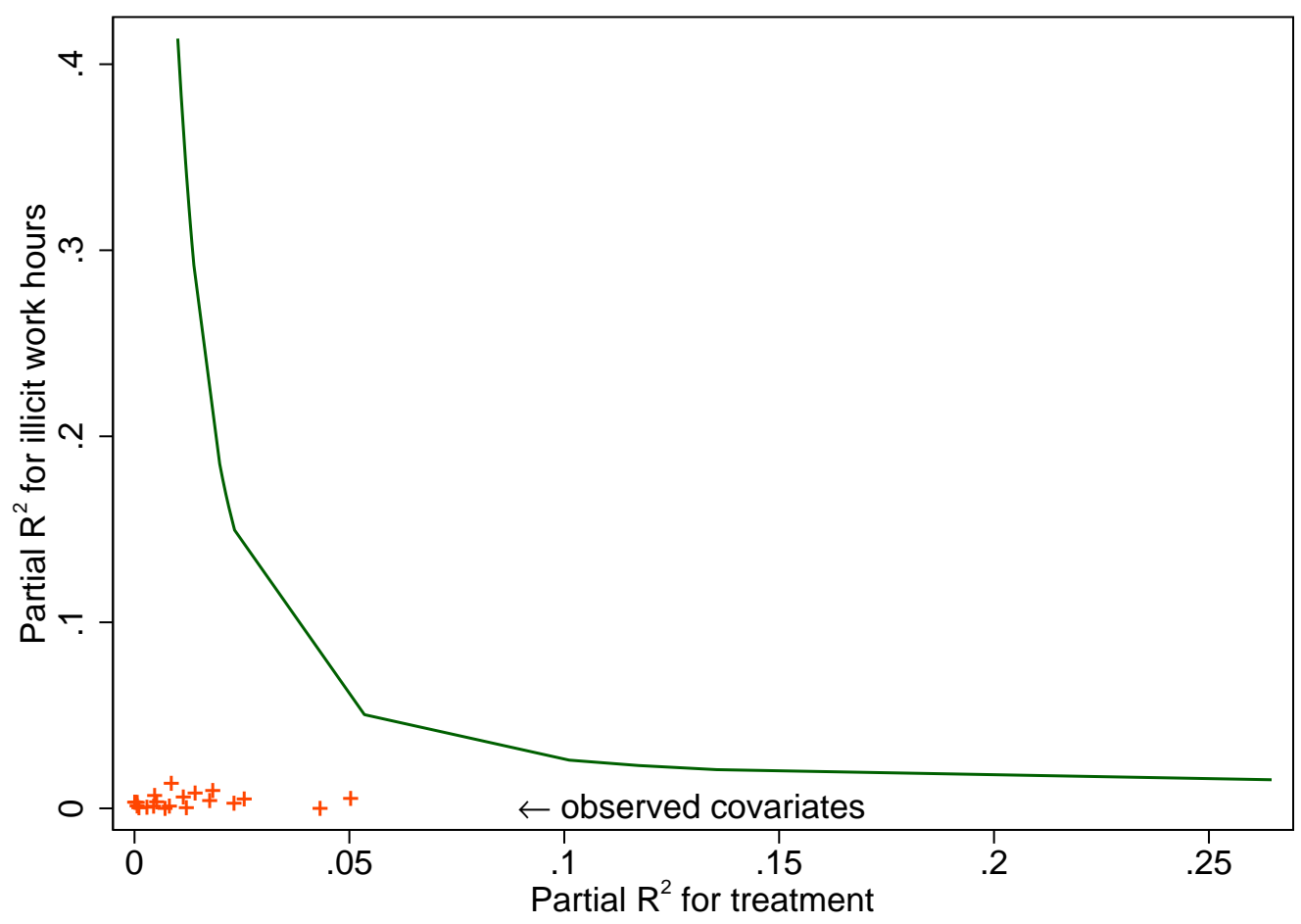

(b) Illicit hours worked per week 


\section{D.4 Heterogeneity by group affiliation/identity}

As discussed in Section 6.3, the Krahn ethnic group was believed to be closely aligned with Gbagbo's side in the Ivoirian war. Indeed, in an OLS regression of support for Gbagbo on Krahn ethnicity and all other baseline covariates, Krahns are 34 percentage points more likely to support Gbagbo (regressions not shown). This is not the case for other groups in the Kru language family, or for ex-fighters from the Liberian armed group MODEL, which had support from Gbagbo. Similarly, we see no groups that report systematically higher support for Ouattara's side in the conflict, including Liberian Muslims and former members of the ethnically-Muslim rebel group ULIMO-K. Hence Krahn identity, though there are only 21 in our sample, is a string indicator of solidarity with Gbagbo.

In Table D.11 we interact Krahn identity with treatment and examine the effects on illicit hours and recruitment activities. We can see that the Krahn identity (the coefficient on the indicator alone) is associated with 4.1 more illicit hours per week and a one standard deviation increase in recruitment interest and action according to our index of proxies. The overall treatment effects are preserved in the full sample, though they are slightly smaller in magnitude. The coefficient on the interaction between treatment and Krahn, however, is large and negative. It effectively cancels out the heightened effect of simply being Krahn,

and then some. That is, the treatment appears to neutralize the elevated levels of insecurity among Krahns especially. 
Table D.11: Heterogeneity by ethnic affiliation to armed groups

\begin{tabular}{|c|c|c|}
\hline \multirow{3}{*}{ Covariate } & \multicolumn{2}{|c|}{ Dependent variable } \\
\hline & $\begin{array}{l}\text { Hours per week in } \\
\text { illicit activities }\end{array}$ & $\begin{array}{c}\text { All recruitment } \\
\text { interest/actions, } \\
\text { z-score }\end{array}$ \\
\hline & $(1)$ & $(2)$ \\
\hline \multirow[t]{2}{*}{ Assigned to treatment } & -2.995 & -0.135 \\
\hline & {$[1.422]^{* *}$} & {$[.063]^{* *}$} \\
\hline \multirow[t]{2}{*}{ Assigned to treatment $\times$ Krahn ethnicity } & -17.413 & -1.131 \\
\hline & {$[9.000]^{*}$} & {$[.585]^{*}$} \\
\hline \multirow[t]{2}{*}{ Krahn ethnicity } & 4.104 & 1.045 \\
\hline & {$[6.847]$} & {$[.520]^{* *}$} \\
\hline Mean of dependent variable, control group & 15.57 & 0.09 \\
\hline
\end{tabular}

Notes: The table displays OLS regressions of the dependent variable on the listed covariates plus all other baseline covariates and strata fixed effects (not displayed). Standard errors clustered at the community level.

$* * * \mathrm{p}<0.01,{ }^{* *} \mathrm{p}<0.05, * \mathrm{p}<0.1$ 


\section{D.5 Heterogeneity analysis using expanded indices}

Table D.12: Heterogeneity of program impacts by package choice, with expanded economic outcomes

\begin{tabular}{|c|c|c|c|c|c|c|}
\hline \multirow[b]{3}{*}{ Outcome } & \multicolumn{6}{|c|}{ ITT estimates } \\
\hline & \multicolumn{2}{|c|}{$\begin{array}{l}\text { Impact of } \\
\text { assignment to } \\
\text { program }\end{array}$} & \multicolumn{2}{|c|}{$\begin{array}{c}\text { Marginal effect of } \\
\text { choosing animals } \\
\text { package }\end{array}$} & \multicolumn{2}{|c|}{$\begin{array}{l}\text { Program impact on } \\
\text { animal choosers } \\
\qquad(2+4)\end{array}$} \\
\hline & $\begin{array}{c}\text { Coeff. } \\
\text { (1) }\end{array}$ & $\begin{array}{l}\text { Std. Err. } \\
\text { (2) }\end{array}$ & $\begin{array}{c}\text { Coeff. } \\
(3)\end{array}$ & $\begin{array}{c}\text { Std. Err. } \\
\text { (4) }\end{array}$ & $\begin{array}{c}\text { Coeff. } \\
(5)\end{array}$ & $\begin{array}{c}\text { Std. Err. } \\
(6)\end{array}$ \\
\hline \multicolumn{7}{|l|}{ Agricultural engagement: } \\
\hline Raising crops/animals $\dagger$ & 0.127 & {$[0.033]^{* * *}$} & -0.046 & {$[0.045]$} & 0.081 & {$[0.041]^{* *}$} \\
\hline Acres under cultivation & 1.148 & {$[2.360]$} & 2.179 & {$[5.604]$} & 3.327 & {$[5.097]$} \\
\hline Thinks farming is a good living & 0.006 & {$[0.016]$} & 0.010 & {$[0.028]$} & 0.016 & {$[.029]$} \\
\hline Interested in farming & 0.075 & {$[0.031]^{* *}$} & 0.083 & {$[0.041]^{* *}$} & 0.158 & {$[.043]^{* * *}$} \\
\hline Interested in raising animals & 0.047 & {$[0.020]^{* *}$} & 0.014 & {$[0.022]$} & 0.060 & {$[.023]^{* * *}$} \\
\hline Hours worked/week, past month & 2.502 & {$[2.616]$} & -8.065 & {$[5.190]$} & -5.563 & {$[4.757]$} \\
\hline Illicit resource extraction & -2.318 & {$[1.406]$} & -2.706 & {$[2.490]$} & -5.024 & {$[2.484]^{* *}$} \\
\hline Logging & -0.767 & {$[0.695]$} & -0.842 & {$[1.116]$} & -1.609 & {$[1.07]$} \\
\hline Mining & -1.109 & {$[1.227]$} & -1.306 & [1.923] & -2.415 & {$[1.859]$} \\
\hline Rubber tapping & -0.442 & {$[0.567]$} & -0.558 & {$[0.948]$} & -1.000 & [1.041] \\
\hline Farming and animal-raising & 4.004 & {$[1.342]^{* * *}$} & -4.621 & {$[2.314]^{* *}$} & -0.617 & {$[2.001]$} \\
\hline Farming & 3.503 & {$[1.198]^{* * *}$} & -4.675 & {$[1.884]^{* *}$} & -1.172 & {$[1.571]$} \\
\hline Animal-raising & 0.501 & {$[0.579]$} & 0.054 & [1.321] & 0.555 & {$[1.157]$} \\
\hline Contract agricultural labor & -0.321 & {$[0.331]$} & 1.086 & {$[1.188]$} & 0.765 & {$[1.104]$} \\
\hline Palm, coconut, sugar cutting & 0.252 & {$[0.363]$} & 0.066 & {$[0.315]$} & 0.318 & {$[0.376]$} \\
\hline Hunting & 0.378 & {$[0.352]$} & -0.862 & {$[0.381]^{* *}$} & -0.484 & {$[0.427]$} \\
\hline Non-farm labor and business & 0.178 & {$[2.280]$} & -1.840 & {$[3.196]$} & -1.662 & {$[2.919]$} \\
\hline Other activities & 0.330 & {$[0.581]$} & 0.812 & {$[1.079]$} & 1.142 & {$[1.109]$} \\
\hline \multicolumn{7}{|l|}{ Other illicit activities: } \\
\hline Any illicit resource extraction & -0.014 & {$[0.032]$} & -0.057 & {$[0.051]$} & -0.071 & {$[0.056]$} \\
\hline Sells any soft or hard drugs & -0.007 & {$[0.012]$} & -0.007 & {$[0.015]$} & -0.013 & {$[0.014]$} \\
\hline Stealing activities (z-score) $\dagger$ & 0.054 & {$[0.065]$} & -0.043 & {$[0.082]$} & 0.012 & {$[0.096]$} \\
\hline
\end{tabular}

Notes: Column (1) reports the ITT coefficient of program assignment and Column (3) reports the coefficient on an interaction between program assignment and choosing poultry/pigs. Column (5) lists the sum of the coefficients in Columns (1) and (3). The regression includes baseline covariates and regional dummies are used instead of block dummies. Robust standard errors in brackets, clustered by community.

*** $\mathrm{p}<0.01, * * \mathrm{p}<0.05, * \mathrm{p}<0.1$ 
Table D.13: Heterogeneity of program impacts by package choice, with expanded economic outcomes

\begin{tabular}{|c|c|c|c|c|c|c|}
\hline \multirow[b]{3}{*}{ Outcome } & \multicolumn{6}{|c|}{ ITT estimates } \\
\hline & \multicolumn{2}{|c|}{$\begin{array}{l}\text { Impact of } \\
\text { assignment to } \\
\text { program }\end{array}$} & \multicolumn{2}{|c|}{$\begin{array}{c}\text { Marginal effect of } \\
\text { choosing animals } \\
\text { package }\end{array}$} & \multicolumn{2}{|c|}{$\begin{array}{l}\text { Program impact on } \\
\text { animal choosers } \\
\qquad(2+4)\end{array}$} \\
\hline & $\begin{array}{l}\text { Coeff. } \\
(1)\end{array}$ & $\begin{array}{l}\text { Std. Err. } \\
\quad(2)\end{array}$ & $\begin{array}{l}\text { Coeff. } \\
(3)\end{array}$ & $\begin{array}{l}\text { Std. Err. } \\
\text { (4) }\end{array}$ & $\begin{array}{l}\text { Coeff. } \\
(5)\end{array}$ & $\begin{array}{l}\text { Std. Err. } \\
\quad(6)\end{array}$ \\
\hline Direct recruitment activities $(0-12)$ & -0.157 & {$[0.107]$} & -0.138 & {$[0.142]$} & -0.295 & {$[.13]^{* *}$} \\
\hline $\begin{array}{l}\text { Direct recruitment activities excluding } \\
\text { "Talked to a commander" }(0-11)\end{array}$ & -0.072 & {$[0.098]$} & -0.150 & {$[0.129]$} & -0.222 & {$[.105]^{* *}$} \\
\hline Talked to a commander in last 3 months & -0.085 & {$[0.040]^{* *}$} & 0.013 & {$[0.068]$} & -0.073 & {$[.064]$} \\
\hline Would go if called to fight for tribe & -0.008 & {$[0.012]$} & -0.017 & {$[0.015]$} & -0.025 & {$[.015]$} \\
\hline Has been approached about going to CI & 0.007 & {$[0.019]$} & -0.032 & {$[0.027]$} & -0.025 & {$[.025]$} \\
\hline Would go to CI for $\$ 250$ & -0.007 & {$[0.010]$} & 0.013 & {$[0.012]$} & 0.006 & {$[.005]$} \\
\hline Would go to CI for $\$ 500$ & -0.012 & {$[0.013]$} & 0.024 & {$[0.019]$} & 0.013 & {$[.014]$} \\
\hline Would go to CI for $\$ 1000$ & -0.032 & {$[0.017]^{*}$} & 0.000 & {$[0.027]$} & -0.031 & {$[.026]$} \\
\hline Will move towards CI border area & -0.008 & {$[0.022]$} & -0.048 & {$[0.027]^{*}$} & -0.056 & {$[.025]^{* *}$} \\
\hline Invited to secret meeting on going to CI & 0.007 & {$[0.014]$} & -0.023 & {$[0.020]$} & -0.016 & {$[.021]$} \\
\hline Attended secret meeting on going to CI & -0.007 & {$[0.009]$} & -0.011 & {$[0.015]$} & -0.019 & {$[.015]$} \\
\hline Was promised money to go to CI & 0.008 & {$[0.013]$} & -0.038 & {$[0.016]^{* *}$} & -0.030 & {$[.014]^{* *}$} \\
\hline Willing to fight if war breaks out in CI & -0.009 & {$[0.014]$} & -0.027 & {$[0.024]$} & -0.036 & {$[.018]^{* *}$} \\
\hline Has plans to go to CI in the next month & -0.011 & {$[0.009]$} & 0.008 & {$[0.013]$} & -0.003 & {$[.01]$} \\
\hline Indirect recruitment measures $(0-4)$ & -0.080 & {$[0.066]$} & -0.217 & {$[0.091]^{* *}$} & -0.296 & {$[.097]^{* * *}$} \\
\hline Talks about the CI violence with friends & -0.014 & {$[0.036]$} & -0.115 & {$[0.054]^{* *}$} & -0.129 & {$[.055]^{* *}$} \\
\hline Has a partisan preference in $\mathrm{CI}$ & -0.080 & {$[0.035]^{* *}$} & -0.049 & {$[0.060]$} & -0.129 & {$[.06]^{* *}$} \\
\hline Knows people who went to CI to fight & -0.011 & {$[0.016]$} & -0.027 & {$[0.027]$} & -0.038 & {$[.027]$} \\
\hline Knows people given money to go to CI & 0.025 & {$[0.014]^{*}$} & -0.025 & {$[0.025]$} & -0.001 & {$[.024]$} \\
\hline
\end{tabular}

Notes: Column (1) reports the ITT coefficient of program assignment and Column (3) reports the coefficient on an interaction between program assignment and choosing poultry/pigs. Column (5) lists the sum of the coefficients in Columns (1) and (3). The regression includes baseline covariates and regional dummies are used instead of block dummies. Robust standard errors in brackets, clustered by community.

$* * * \mathrm{p}<0.01,{ }^{* *} \mathrm{p}<0.05, * \mathrm{p}<0.1$ 